\title{
O problema de alocação de efluentes sanitários: uma revisão sistemática da literatura
}

\section{The waste load allocation problem: a systematic literature review}

Data de entrada: 18/12/2019

- Data de aprovação: 23/03/2020

Thiara Cezana Gomes ${ }^{1 * *}$ | Antonio Sergio Ferreira Mendonça ${ }^{1}$ | José Antônio Tosta dos Reis' | Rodrigo de Alvarenga Rosa ${ }^{1}$

DOI: https://doi.org/10.36659/dae.2021.058

ORCID ID

Gomes TC (D) https://orcid.org/0000-0002-6279-4008

Mendonça ASF (ID) https://orcid.org/0000-0003-4273-0266

Reis JAT (ID) https://orcid.org/0000-0001-9916-1469

Rosa RA (i) https://orcid.org/0000-0003-0841-514X

\section{Resumo}

No Brasil, os níveis de cobertura dos serviços de tratamento de esgotos ainda são considerados baixos. Os custos de implantação, operação e manutenção de sistemas de tratamento de esgotos são, em geral, elevados e variam consideravelmente conforme o tipo de tecnologia a ser implementada. Assim, modelos matemáticos capazes de auxiliar o processo de alocação da carga orgânica e o consequente processo de seleção dessas tecnologias são de grande valia para a gestão adequada dos recursos hídricos. Diante da relevância do assunto, este artigo tem como objetivo realizar uma revisão sistemática das principais publicações relacionadas ao Problema de Alocação de Efluentes Sanitários (PAES). O intuito é analisar publicações recentes e identificar abordagens de solução, cenários de aplicação, características incorporadas aos modelos de otimização e lacunas científicas existentes.

Palavras-chave: Problema de alocação de efluentes sanitários. Modelo de qualidade de água. Tratamento de esgoto. Sistemas de águas residuárias. Otimização.

\section{Abstract}

In Brazil, the sewage treatment services coverage levels are low. The sewage treatment systems setting up, operating and maintaining costs are generally high and vary considerably depending on the technology type to be implemented. Thus, mathematical models capable of assisting the organic load allocation and the consequent technologies selection processes are of great value for the adequate water resources management. Given the subject relevance, this article aims to conduct a systematic review of the main publications related to the Waste Load Allocation (WLA) problem. It aims to analyze recent publications and identify solution approaches, application scenarios, optimization models features and existing scientific gaps.

Keywords: Waste load allocation problem. Water quality model. Sewage treatment. Wastewater systems. Optimization.

\footnotetext{
${ }^{1}$ Universidade Federal do Espírito Santo (UFES) - Vitória - Espírito Santo - Brasil.

* Autora correspondente: thiaracezanaahotmail.com.
} 


\section{INTRODUÇÃO}

Atualmente, a parcela atendida com coleta e tratamento de esgotos em municípios brasileiros representa menos da metade da população urbana total. Além disso, de toda a carga orgânica gerada, apenas $39 \%$ é removida com a infraestrutura de tratamento de esgotos existente nas sedes das cidades do país. Dessa maneira, aproximadamente 5,5 mil toneladas DBO/dia podem alcançar os corpos receptores. No Brasil, o montante de investimento estimado até 2035 para universalizar os serviços de esgotamento sanitário, de maneira a aumentar a segurança hídrica em termos de qualidade da água, é cerca de $\mathrm{R} \$ 150$ bilhões (ANA, 2017).

No que concerne à escolha das melhores formas de tratamento de efluentes e das localizações de estações de tratamento de esgoto (ETEs), estações elevatórias (EEs) e condutos que compõem um sistema regional de tratamento de efluentes (SRTE), nota-se que o uso de modelos de otimização pode auxiliar no processo de tomada de decisão (MACHADO; PORTO; KAVISKI, 2012). O objetivo desses modelos é quase sempre o mesmo: minimizar custos de implantação, operação e manutenção da rede e maximizar a melhoria da qualidade da água (MACHADO; CUNHA; PORTO, 2006). Do ponto de vista prático, não há uma solução única para projetar um sistema de águas residuárias: possíveis soluções incluem o tratamento individualizado da carga orgânica gerada em cada comunidade, mas também há a possibilidade de projetar sistemas em que todo o montante de água residuária da região seja tratado em uma estação centralizada (CUNHA et al., 2005).

Nesse contexto, este artigo tem por objetivo realizar uma revisão sistemática das principais publicações relacionadas ao Problema de Alocação de Efluentes Sanitários (PAES). $O$ intuito é analisar o que foi estudado até o momento e identificar abordagens de solução, características dos modelos e lacunas científicas.
Há dois artigos de revisão da literatura relevantes sobre esse tema: Melo e Câmara (1994) e Machado, Cunha e Porto (2006). Melo e Câmara (1994) apresentaram diferentes estudos desenvolvidos para planejamento de sistemas regionais de tratamento de efluentes. A discussão deu-se quanto a três itens principais dos modelos: definição da função objetivo e restrições; método de otimização usado e aplicabilidade prática desses modelos. Machado, Cunha e Porto (2006) propuseram uma taxonomia na qual a classe de problemas foi dividida em dois grupos: (i) Modelos para estações de tratamento de efluentes (ETES) individuais: engloba alocação ótima de cargas, minimização de custos e considerações de equidade; (ii) Modelos para estações de tratamento de efluentes (ETES) regionais ou centralizadas: usados para determinar quais estações de tratamento de efluentes (ETE) devem ser alocadas entre $n$ possíveis locais de instalação (MACHADO; CUNHA; PORTO, 2006; CUNHA et al., 2009; ZEFERINO, 2011).

No entanto, o presente artigo tem como diferencial em relação aos anteriores os seguintes pontos: (i) a inclusão de publicações recentes, dos anos 2000 a 2019, que até então não haviam sido consideradas; (ii) o uso de metodologia específica para efetuar a revisão (BRERETON et al., 2007); (iii) a inclusão de novos itens na definição da função objetivo e restrições; (iv) a realização de análises que incluem a distribuição geográfica dos artigos.

O artigo é organizado, além desta Introdução, como segue: na Seção 2 são expostos conceitos essenciais para entendimento do problema de alocação de efluentes sanitários; na Seção 3 apresenta-se a metodologia utilizada para a revisão sistemática; na Seção 4 têm-se a descrição da revisão sistemática e os resultados obtidos; e a Seção 5 contém as considerações finais. 


\section{METODOLOGIA}

Usualmente, bacias hidrográficas apresentam séries de pontos de disposição final de efluentes com consideráveis variações qualitativas e quantitativas, e cursos d'água com características hidrodinâmicas substancialmente diferentes. Assim, o processo de alocação de cargas poluidoras tende a ser complexo. Ao longo dos anos, foi possível minimizar a complexidade da resolução dos problemas de alocação de efluentes sanitários (PAES) por meio do uso de técnicas de otimização (VALORY; REIS; MENDONÇA, 2016).

De maneira geral, modelos de otimização são compostos por função objetivo, que se deseja maximizar e/ou minimizar, e o conjunto de restrições, na forma de equações e/ou inequações, que determinam a região viável das variáveis de decisão (MEZURA-MONTES; COELLO, 2008). Tipicamente, modelos de alocação de cargas efluentes visam à determinação do nível necessário de remoção de poluentes para cada fonte, de tal maneira que a solução de custo global mínimo seja obtida, mantendo ou alcançando de forma satisfatória a qualidade hídrica (BURN; YULIANTI, 2001; MAHJOURI; BIZHANI-MANZAR, 2013;
ASHTIANI et al., 2015a; SAADATPOUR, AFSHAR; KHOSHKAM, 2019). Ou seja, tem-se como variável de decisão o nível de tratamento necessário para as diferentes fontes pontuais; as restrições que garantem a obediência aos padrões de qualidade de água, conforme carga de poluentes, condições do corpo receptor e legislação vigente; enquanto a função objetivo, normalmente, visa maximizar alguma medida de eficiência econômica (BURN; YULIANTI, 2001).

O PAES envolve complexos fatores sociais, econômicos, ambientais e políticos. Assim, a alocação de carga precisa ser economicamente eficiente, tecnicamente viável e socialmente justa (LIU et al., 2014; SAADATPOUR; AFSHAR; KHOSHKAM, 2019). Nas últimas décadas, impulsionado pela conscientização quanto aos quatro pilares citados anteriormente e pelo aprimoramento das técnicas computacionais, o uso de funções com múltiplos objetivos cresceu consideravelmente (BRAGA; BARBOSA; NAKAYAMA, 1998; ASHTIANI et al., 2015a). A Fig. 1 ilustra alguns dos principais itens que podem compor a função objetivo e as restrições desse tipo de problema, tornando a abordagem mais abrangente e realista.

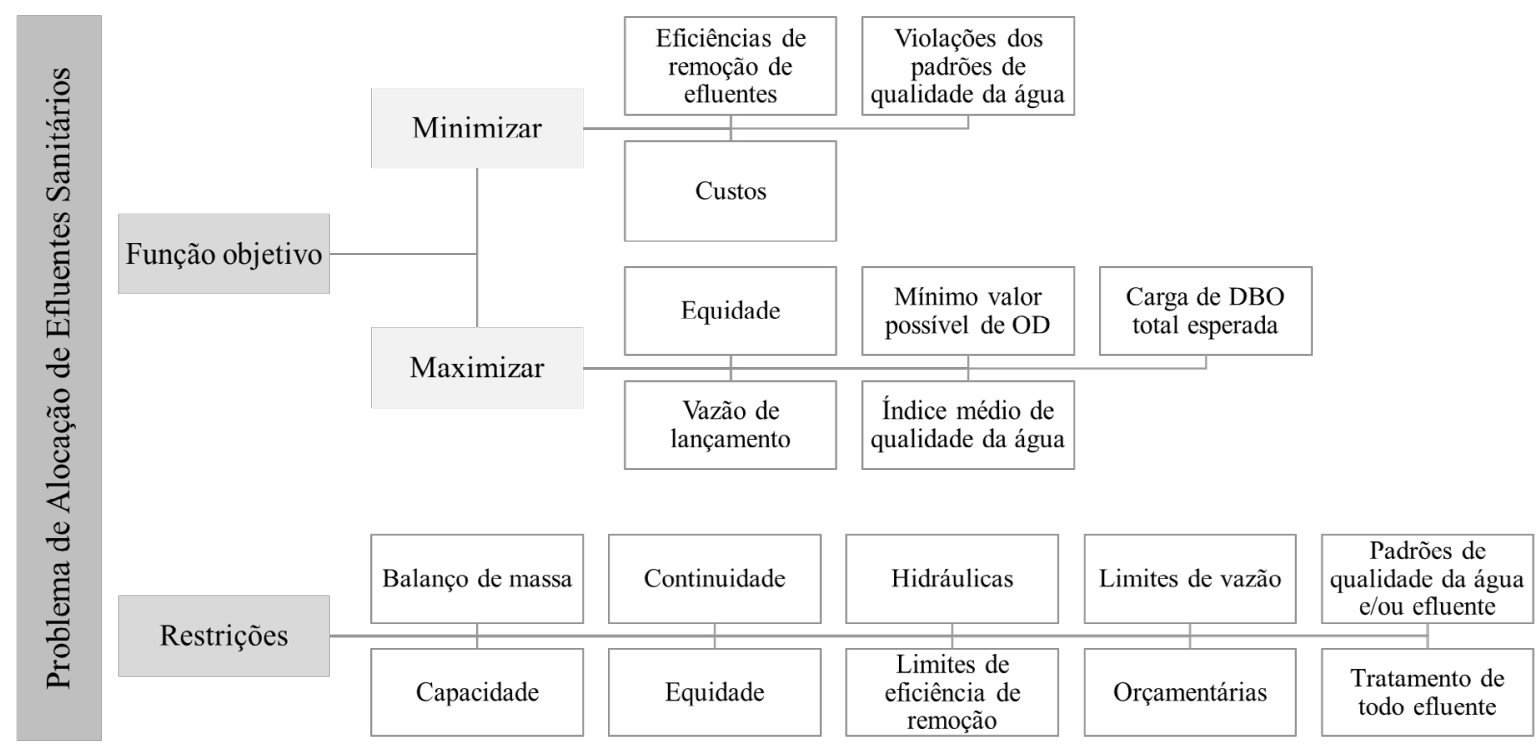

Figura 1 - Principais função objetivo e restrições dos modelos de alocação de efluentes sanitários 
É sabido que a escolha entre os diferentes objetivos e restrições do PAES pode variar conforme especificidades da região de aplicação do modelo. Isso inclui, dentre outros, o grau de desenvolvimento do país de instalação dos sistemas de tratamento de esgotos. Isto é, em países desenvolvidos a eficiência do sistema, a confiabilidade e requisitos de área são critérios mais críticos a serem analisados. Em contrapartida, em países em desenvolvimento, a minimização dos custos tende a ser um ponto de grande relevância (METCALF; EDDY, 1991; VON SPERLING, 2007; VON SPERLING, 2014). Ainda sobre países subdesenvolvidos, duas questões crescem em importância: (i) o uso da capacidade de autodepuração do rio, justificado pela carência de recursos financeiros, desde que considerada parcimônia, dentro de critérios técnicos seguros e bem definidos (VON SPERLING, 2014), e (ii) o rateio das capacidades de assimilação dos cursos d'água (LANNA, 1997). O rateio deve atender princípios de equidade e distribuição de custos, definindo quanto e quem deve pagar pelos danos provenientes da poluição. Desta forma, busca-se evitar que um só poluidor utilize toda a capacidade de assimilação dos cursos d'água (LANNA, 1997; BRINGER, 2017).

Os níveis de tratamento para um dado conjunto de fontes poluentes são afetados pelas capacidades de assimilação dos corpos receptores. Por isso, frequentemente um modelo de quali- dade da água é combinado a algum algoritmo determinístico ou probabilístico para predizer a resposta do rio em termos de determinados parâmetros de análise (YANDAMURI; SRINIVASAN; BHALLAMUDI, 2006; MOSTAFAVI; AFSHAR, 2011; LEl et al., 2015). A resposta dependerá da carga de poluentes e das condições dentro do corpo d'água, como fluxos de água, temperaturas, taxas de reação e taxas de sedimentação (BURN; YULIANTI, 2001).

Os modelos de qualidade da água são formados por um conjunto de expressões matemáticas que definem os processos físicos, químicos e biológicos que ocorrem no corpo d'água (RAUCH et al., 1998). A formulação original de StreeterPhelps é composta, de forma genérica, por duas equações diferenciais ordinárias: uma modela a desoxigenação, ou seja, a oxidação da matéria orgânica biodegradável, e a outra a reaeração atmosférica (STREETER; PHELPS, 1925). Ao longo dos anos, a formulação clássica foi passando por aperfeiçoamentos e incorporações de diferentes processos (COX, 2003; CHAPRA, 2008). Segundo Wang et al. (2013), o processo de desenvolvimento dos modelos de qualidade de água pode ser dividido em três fases. A Fig. 2 sumariza os principais modelos surgidos nas décadas subsequentes à concepção do modelo de StreeterPhelps, conforme Calmon (2015); Rauch et al., (1998) e Wang et al. (2013). 


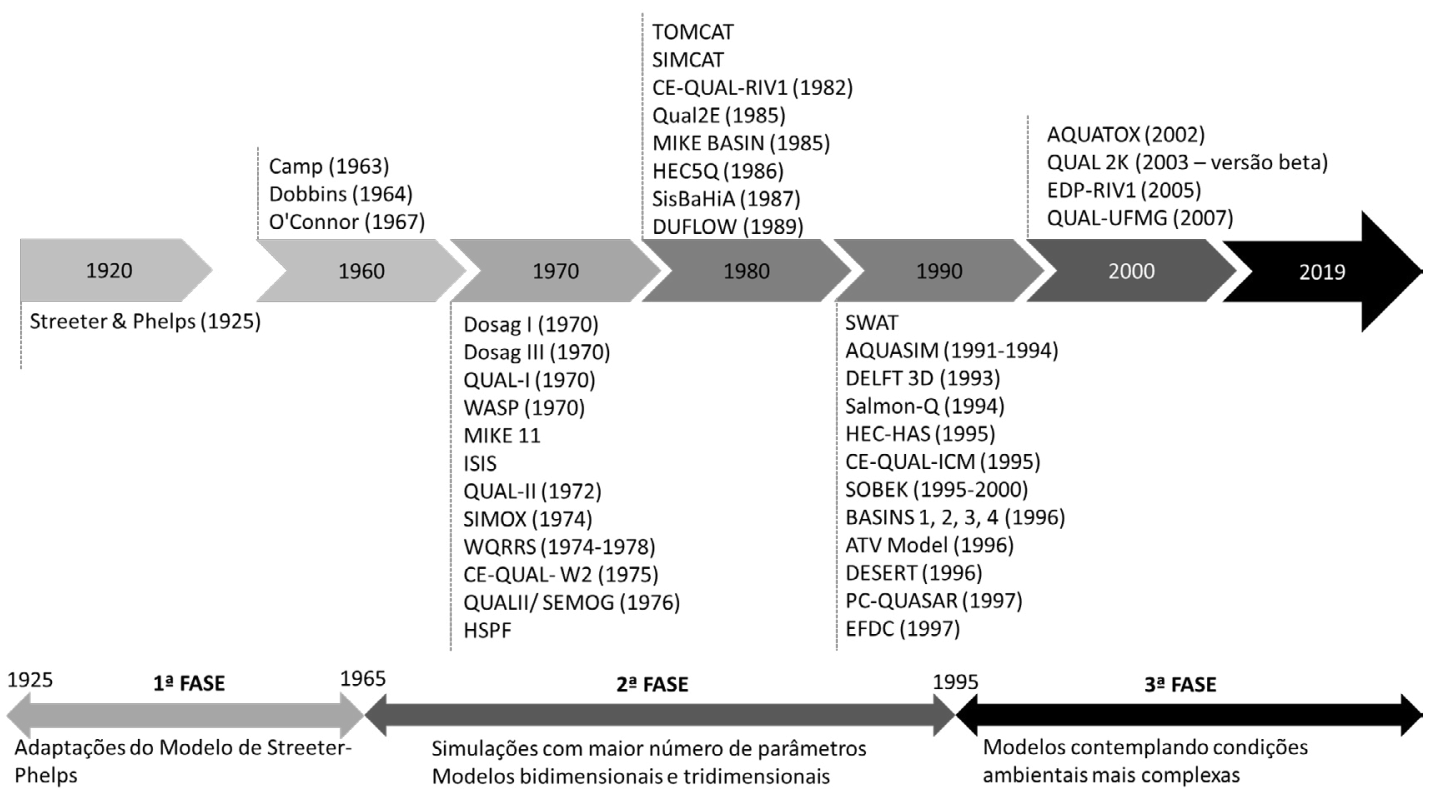

Figura 2 - Linha do tempo dos modelos matemáticos de qualidade de água

\section{METODOLOGIA}

A revisão sistemática de literatura é uma forma de estudo que utiliza uma metodologia bem definida para identificar, analisar e sumarizar as evidências disponíveis a respeito de uma questão de pesquisa particular de maneira imparcial e repetível (OKOLI; SCHABRAM, 2010). Um método de revisão sistemática da literatura constituído por três fases (Fig. 3) foi proposto por Brereton et al. (2007) para o domínio da engenharia de software. Posteriormente, Arpini e Rosa (2017) aplicaram-no para o Problema de Roteirização de Veículos Capacitados com Restrições de Carregamento Bidimensional (2L-CVRP), demonstrando a flexibilidade do método em diferentes áreas de concentração da engenharia.

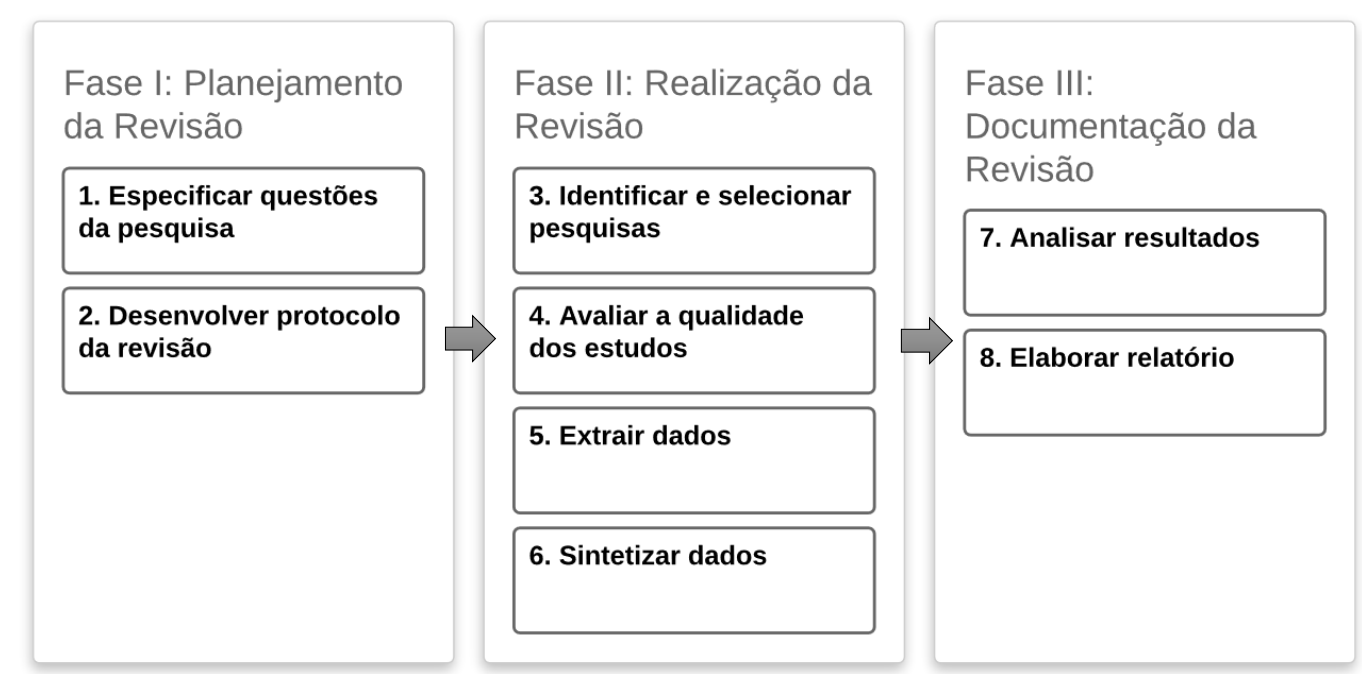

Figura 3 - Etapas da revisão sistemática. Fonte: Adaptado de Brereton et al. (2007). 
Conforme Fig. 3, a Fase I é composta por duas etapas: (1) Especificar questões da pesquisa e (2) Desenvolver protocolo da revisão. Assim, devem-se definir o tema abordado, os objetivos e o procedimento que serão adotados para realizar a revisão. A Fase Il contém quatro etapas: (3) Identificar e selecionar pesquisas; (4) Avaliar a qualidade dos estudos; (5) Extrair dados; (6) Sintetizar dados. Nessa fase, os critérios para seleção e avaliação dos trabalhos identificados e a organização da informação extraída são elaborados. A Fase III apresenta duas etapas: (7) Analisar resultados e (8) Elaborar relatório.

\section{APLICAÇÃO DA METODOLOGIA E RESULTADOS ENCONTRADOS}

Nesta seção apresentam-se a aplicação da metodologia ilustrada na Fig. 3 bem como os resultados obtidos.

\subsection{Fase I: Planejamento da Revisão}

Esta subseção descreverá as etapas relacionadas à Fase $\mathrm{I}$.

\subsubsection{Etapa 1: Especificar questões da pesquisa}

No que diz respeito ao problema de alocação de efluentes sanitários, esta revisão visa responder às seguintes questões 1) Quais as abordagens de solução empregadas?; 2) Quais características são incorporadas ao problema?; 3) O modelo de otimização foi executado em instâncias reais ou de teste?; 4) Em qual país a metodologia foi aplicada?; 5) Qual o modelo de qualidade de água foi utilizado?; 6) Quais os parâmetros de qualidade da água analisados?; 7) Quais as lacunas existentes na literatura?.

\subsubsection{Etapa 2: Desenvolver protocolo da revisão}

Para identificar as pesquisas efetuaram-se buscas nas bases Science Direct, IEEE Xplore, Wiley
Online Library, Scielo, Scopus e Domínio Público, além da plataforma de busca do Google Scholar, utilizando como palavras-chave "waste load allocation"; "water quality modelling"; "optimization”; "river basin”; "problema de alocação de efluentes sanitários"; "modelagem de qualidade de água"; "otimização"; "bacia hidrográfica". As palavras-chave foram procuradas no título, no resumo e nas palavras-chave dos estudos.

Considerou-se o período de 2000 a 2019 para a realização deste trabalho considerando este um horizonte de tempo satisfatório para caracterizar o cenário das pesquisas e sua evolução. Não houve limitação quanto ao país de publicação. Para selecionar as pesquisas identificadas, foram considerados artigos científicos publicados em periódicos relacionados às áreas de engenharia ambiental, recursos hídricos, saneamento, engenharia civil e computação que tratam do PAES. Foram pesquisados artigos nos idiomas inglês e português. Monografias de curso de pós-graduação, trabalhos de cursos de graduação, dissertações, teses, capítulos de livro e publicações de simpósios, congressos ou conferências foram excluídos da pesquisa. Ressalta-se que artigos que tratassem do PAES, mas sem a inclusão de algum tipo de modelo de otimização, também foram desconsiderados. Isto porque toda a estrutura da tabela-resumo, apresentada na seção 4.2.4, foi feita com base em objetivos e restrições típicos de modelos de otimização.

Para avaliar a qualidade dos estudos, fez-se a leitura completa dos trabalhos selecionados e foram utilizados critérios de inclusão específicos. O critério de inclusão englobou estudos que contivessem abordagens de solução de otimização e realização de testes em instâncias de referência da literatura ou instâncias reais com dados de rios ou bacias hidrográficas. Aplicações em reservatórios e estuários foram desconsideradas. 
A partir dos estudos que atenderam aos critérios expostos anteriormente, extraíram-se dados relativos a três categorias que se subdividem em demais itens, conforme esquema da Fig. 4. A listar: (i) Referências (autor; ano; periódico), (ii) Aplicação (cenário hipotético; cenário real; bacia hidrográfica e país de aplicação; número de fon- tes geradoras de esgoto avaliadas); (iii) Modelagem (abordagens de solução; modelo de qualidade da água utilizado; modelo de otimização (função objetivo; restrições). Os itens incluídos nas subcategorias "função objetivo" e "restrições" na categoria "Modelagem" são os contemplados na Fig. 4.

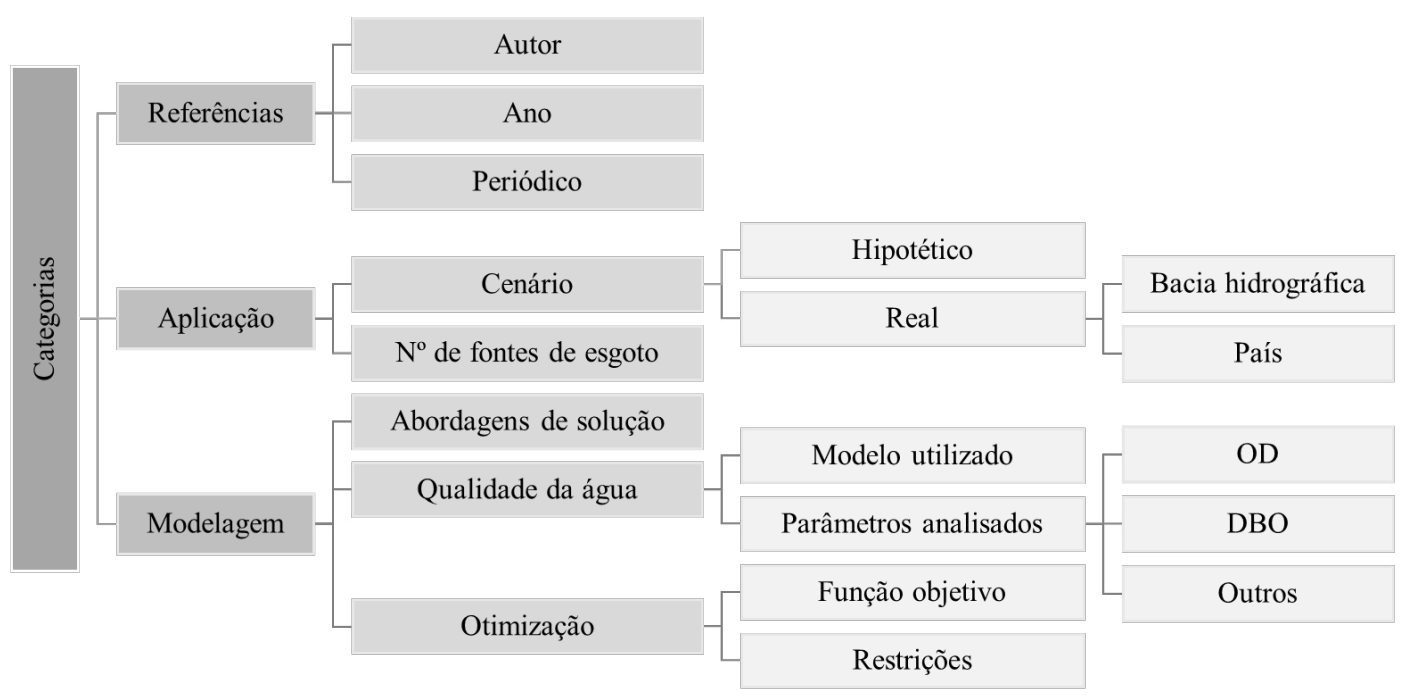

Figura 4 - Estrutura da revisão da literatura

\subsection{Fase II: Documentação da Revisão}

Nesta subseção abordam-se as quatro etapas associadas à Fase II.

\subsubsection{Etapa 3: Identificar e Selecionar Pesquisas}

A identificação e a seleção dos trabalhos seguiram os critérios apresentados na seção 4.1.2, resultando, inicialmente, na identificação de cinquenta e três estudos.

\subsubsection{Etapa 4: Avaliar a qualidade dos estudos}

Por meio da leitura completa dos trabalhos previamente selecionados foram feitas as avaliações de qualidade. Os critérios de inclusão descritos na seção 4.1.2 foram utilizados, ocasionando a exclusão de vinte e cinco artigos que não atenderam aos critérios de inclusão estabelecidos. Dessa ma- neira, foram considerados vinte e oito trabalhos para a realização da revisão sistemática de literatura. Após isso, extraíram-se os dados.

\subsubsection{Etapa 5: Extrair dados}

Quanto às fontes de pesquisa, quatro periódicos concentraram $42,9 \%$ do total de estudos analisados, a listar: Revista Brasileira de Recursos Hídricos (RBRH), Journal of Water Resources Planning and Management, Water Science and Technology e Water Resources Research. A Fig. 5 apresenta a distribuição dos artigos em diferentes revistas. É possível observar a presença frequente de periódicos da área de recursos hídricos e engenharia ambiental, mas também de revistas de engenharia civil e computação. No último caso, devido ao uso frequente de técnicas de otimização para resoluções do PAES. 


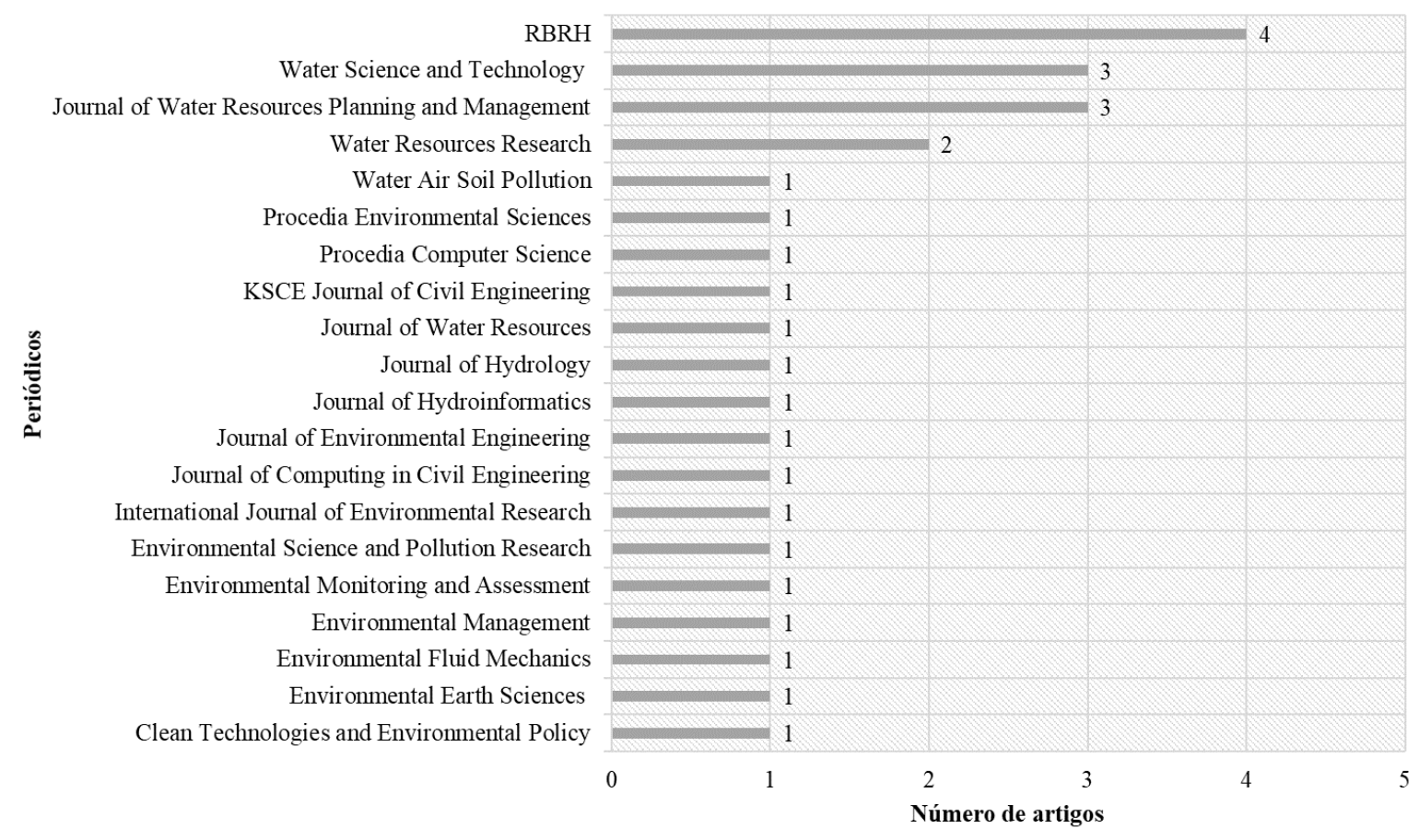

Figura 5 - Q Quantidade de artigos por periódico

Em relação ao período englobado nesta pesquisa, os anos de 2009, 2012, 2015 e 2017 apresentaram maiores quantidades de publicações, conforme Fig. 6. Esse crescimento de publicações na última década pode ser justificado pelo processo de intensa urbanização que abrangeu diversas cidades do mundo, ocasionando a piora na qualidade das águas de diversas bacias hidrográficas. Em consequência, ampliou-se a necessidade de aprimoramento da gestão dos recursos hídricos apoiada, dentre outros, pela solução de proble- mas de alocação de carga efluente (CHO; LEE, 2014; Ll et al., 2015; YU; HE; LU, 2016).

Além disso, o avanço das técnicas computacionais também impulsionou a pesquisa nos últimos anos, possibilitando a elaboração de modelos mais realistas, incluindo múltiplos objetivos, áreas de abrangência maiores, um maior número de parâmetros de qualidade da água e incertezas associadas ao processo (BRAGA; BARBOSA; NAKAYAMA, 1998; HAN et al., 2012; ASHTIANI et al., 2015a; VALORY; REIS; MENDONÇA, 2016).

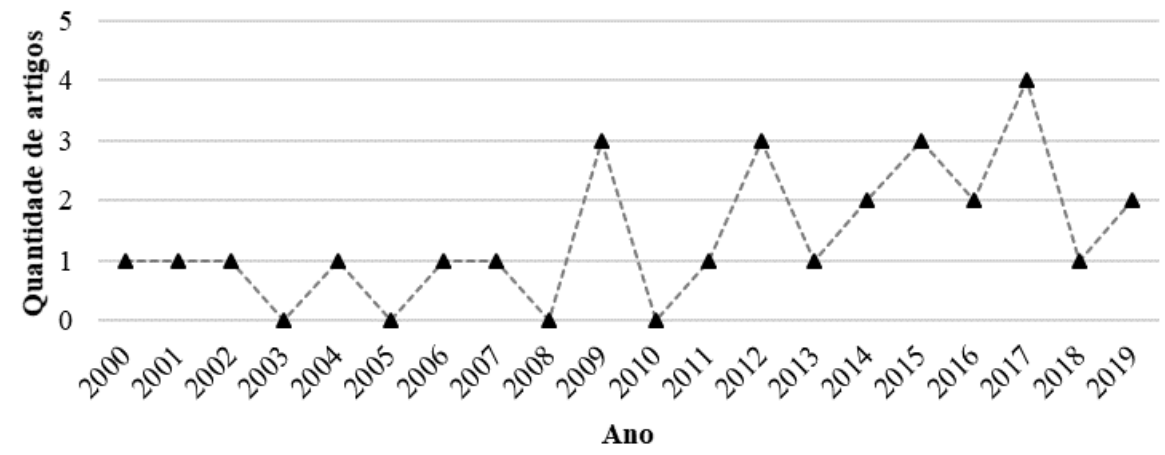

Figura 6 - Evolução do número de publicações por ano 


\subsubsection{Etapa 6: Sintetizar dados}

A síntese dos artigos selecionados, com enfoque na aplicação e modelagem, é apresentada nas Tabelas 1 e 2 . As tabelas sumarizam, em ordem cronológica, a revisão da literatura, sendo os itens elencados nas colunas baseados na revisão sistemática de Melo e Câmara (1994); Machado, Cunha e Porto (2006) e conforme a leitura dos vinte e oito artigos listados. A subdivisão das tabelas segue a estrutura estabelecida por meio da Fig. 4 apresentada anteriormente. Outro ponto a destacar é que, em muitos casos, os estudos objetos de análise tratam de mais de um modelo de otimização. Por isso, fez-se uso de simbologia, conforme rodapé da Tabela 2, para sinalizar a função objetivo e as restrições de cada modelo.

O problema de alocação de efluentes sanitários é frequentemente resolvido usando modelo de qualidade de água acoplado a método de otimização (LOUCKS; REVELLE; LYNN, 1967; DORFMAN; JACOBY; THOMAS, 1972). Com objetivo de criar um processo capaz de escapar de mínimos locais e realizar uma busca robusta no espaço de soluções, ainda que sem garantia de otimalidade, há também o frequente uso de metaheurísticas. Algoritmos Genéticos, Tabu Search, Simulated Annealing, Ant Colony Optimization, Greedy Randomized Adaptive Search Procedure, Particle Swarm Optimization são exemplos de metaheurísticas usadas para resolução de diferentes problemas. Burn e Yulianti (2001), por exemplo, buscaram identificar a viabilidade do uso do Algoritmo Genético (AG) em PAES. Para isso, três diferentes formulações foram propostas e aplicadas a um estudo de caso baseado no rio Willamette em Oregon, Estados Unidos (EUA). Nessas formulações, os autores consideraram os custos e a equidade na distribuição do esforço de tratamento entre os poluidores para definir tradeoffs considerando diferentes objetivos. Resultados demonstraram que o AG é uma técnica de solução eficaz para a resolução do PAES.
No estudo de Aras, Togan e Berkun (2007), o enfoque foi a comparação entre o AG e a Programação Linear proposta por Revelle, Loucks e Lynn (1968) na resolução do PAES. A solução do AG permitiu estimar as eficiências de remoção de demanda bioquímica de oxigênio (DBO) correspondentes às estações de tratamento de efluentes (ETE) considerando um cenário hipotético com três comunidades. $O$ intuito era minimizar o custo do tratamento de águas residuárias para toda a bacia hidrográfica, impondo-se o atendimento de restrições de qualidade da água. Ao final, notou-se que o AG obteve resultados comparáveis aos obtidos por meio da Programação Linear.

Valory, Reis e Mendonça (2016) incorporaram ao PAES padrões de qualidade ambiental para os parâmetros de oxigênio dissolvido (OD) e DBO, além de medidas de equidade entre os sistemas de tratamento de esgoto, tanto nas restrições como na função objetivo. Para isso, um modelo de qualidade de água baseado no modelo QUALUFMG foi combinado a um AG e aplicado à bacia hidrográfica do rio Santa Maria da Vitória, Brasil. Foi empregada, também, uma Técnica de Busca Exaustiva (TBE) para a obtenção da solução ótima. Os resultados obtidos com o $A G$ foram muito próximos aos alcançados com a TBE, com o benefício das buscas exigirem tempo de processamento computacional substancialmente menor. Dentre todos os modelos desenvolvidos, o que produziu o conjunto de menores eficiências correspondeu a uma função objetivo que minimizou a soma das eficiências com restrições de obediência aos padrões de qualidade ambiental.

Santoro, Reis e Mendonça (2016), também com auxílio de AG, avaliaram seis diferentes modelos de otimização aplicáveis à determinação de eficiências mínimas de tratamento de esgotos em bacias hidrográficas. Foi considerada a minimização do somatório das eficiências e a minimização da inequidade entre os esforços de tra- 
tamento de esgotos. Resultados indicaram que a ausência de medidas de equidade ocasionou má distribuição das eficiências de tratamento de efluentes. Além disso, os modelos que incluíram equidade como restrição do problema de otimização não apresentaram respostas consistentes. Isso porque o local de aplicação do estudo (bacia hidrográfica do rio Pardo, Brasil) apresentava lançamentos de cargas orgânicas brutas muito diferentes entre si.

A bacia hidrográfica do rio Pardo também foi utilizada no estudo de Fantin, Reis e Mendonça (2017). Inicialmente, foi realizada a etapa de préseleção de alternativas de tratamento de esgoto tecnicamente viáveis com auxílio de $A G$ acoplado ao modelo de qualidade de água. Em seguida, por meio da ordenação crescente de Custos Presente Líquidos (CPL) associados a cada alternativa de tratamento de esgotos, foi feita a escolha final. Os resultados indicaram que o modelo de otimização que buscou a minimização das eficiências, permitindo uso da capacidade de autodepuração dos cursos d'água, selecionou sistemas de tratamento que variaram da combinação de reatores UASB e lagoas de polimento a sistemas de infiltração lenta, escolhas que apresentaram menores estimativas de CPL. Em contrapartida, a incorporação da equidade entre os sistemas de tratamento aumentou significativamente os custos associados ao tratamento de esgoto para a bacia hidrográfica.

Ainda no âmbito do uso de AG, estudos que incluem a junção de diferentes abordagens de solução são frequentemente encontrados na literatura. Bringer, Reis e Mendonça (2018), por exemplo, combinaram modelo de simulação da qualidade da água, AG e análise multicriterial com o auxílio do método Electre III para selecionar sistemas de tratamento de esgotos. Após etapa de pré-seleção técnica, que considerou três diferentes possíveis cenários de tratamento de esgotos, foi aplicada análise multicriterial, que indicou sistemas de tratamento para cinco localidades pertencentes à bacia hidrográfica do rio Pardo, Brasil. Infiltração Rápida, Biofiltro Aerado Submerso (com Nitrificação), Wetland, Lagoas facultativas e reatores UASB (seguidos ou não de pós-tratamento) foram os mais indicados para os cenários considerados.

Para lidar com diferentes objetivos ou critérios, variações conhecidas como Algoritmos Genéticos Multiobjetivos (AGMO) foram propostas (SRINIVAS; DEB, 1994; ZITZLER; THIELE, 1998; DEB et al., 2002). Os AGMOs constituem abordagem mais adequada para resolver problemas com múltiplos objetivos, categorizando possíveis meIhores respostas em virtude dos critérios avaliados. Yandamuri, Srinivasan e Bhallamudi (2006) utilizaram versão multi-objetivo do AG conhecida por Nondominated Sorting Genetic Algorithm II ou Algoritmo Genético de Classificação por Não Dominância II (NSGA II) (DEB et al., 2002). Os autores discutiram a problemática de alocação de cargas considerando os custos e a equidade na distribuição dos esforços de tratamento entre os poluidores. Dois modelos foram propostos, o primeiro relacionado a Custo-Desempenho e o segundo abordou o trade-off Custo-EquidadePerformance. A utilidade prática foi ilustrada por meio de uma aplicação no rio Willamette, nos EUA.

Cho e Lee (2014) utilizaram o modelo de qualidade de água QUAL2Kw em conjunto com o NSGA-II. Foi buscada minimização das eficiências de tratamento, além da minimização da inequidade entre as descargas de efluentes. Um conjunto de soluções, denominadas Pareto-ótimo, foi gerado pelo NSAG-II, permitindo a avaliação dos diferentes cenários e os pontos críticos de poluição, garantindo a escolha da solução mais equânime e de menor custo. A metodologia foi aplicada ao rio Yeongsan, Coreia do Sul, que sofre com níveis extremos de poluição. 
Tabela 1 - Resumo da revisão da literatura de PAES

\begin{tabular}{|c|c|c|c|c|c|c|c|c|}
\hline \multicolumn{3}{|c|}{ Referências } & \multicolumn{4}{|c|}{ Aplicação } & \multicolumn{2}{|c|}{ Modelagem } \\
\hline Autores & Ano & Periódico & $\begin{array}{l}\text { Cenário } \\
\text { Hipotético }\end{array}$ & Cenário Real & País & $\begin{array}{l}\mathrm{N}^{\circ} \text { de } \\
\text { fontes de } \\
\text { esgoto }\end{array}$ & $\begin{array}{l}\text { Abordagens } \\
\text { de solução }\end{array}$ & $\begin{array}{l}\text { Modelo de } \\
\text { Qualidade da Água } \\
\text { (QA) especificado }\end{array}$ \\
\hline Carmichael et al. & 2000 & Water Resources Research & & Rio Nitra & Eslováquia & 12 & S-O;PNL & QUAL2E \\
\hline Burn et al. & 2001 & $\begin{array}{l}\text { Journal of Water Resources } \\
\text { Planning and Management }\end{array}$ & & Rio Willamette & EUA & 10 & AG & QUAL2E \\
\hline Wang et al. & 2002 & Water Resources Research & & Rio Tâmisa & Inglaterra & 7 & AG; RNA & TOMCAT \\
\hline Mujumdar et al. & 2004 & $\begin{array}{l}\text { Journal of Computing in } \\
\text { Civil Engineering }\end{array}$ & & $\begin{array}{l}\text { Rio Tunga- } \\
\text { Bhadra }\end{array}$ & Índia & 8 & $\begin{array}{c}\text { S-O; } \\
\text { Otimização } \\
\text { Fuzzy; AG; HM }\end{array}$ & QUAL2E \\
\hline Yandamuri et al. & 2006 & $\begin{array}{l}\text { Journal of Water Resources } \\
\text { Planning and Management }\end{array}$ & & Rio Willamette & EUA & 14 & NSGA-II & $\sqrt{ }$ \\
\hline Aras et al. & 2007 & $\begin{array}{l}\text { Environmental Fluid } \\
\text { Mechanics }\end{array}$ & $\sqrt{ }$ & & & 3 & $A G ; P L$ & S\&P \\
\hline Cunha et al. & 2009 & Journal of Water Resources & $\sqrt{ }$ & & & 38 & $\begin{array}{c}\text { SA; } \\
\text { Procedimento } \\
\text { de busca local }\end{array}$ & $\sqrt{ }$ \\
\hline Niksokhan et al. & 2009 & Water Science \& Technology & & Rio Zarjub & Irã & 8 & $\begin{array}{l}\text { NSGA-II; YBT; } \\
\text { CSM; CRG }\end{array}$ & $S \& P$ \\
\hline Qin et al. & 2009 & $\begin{array}{l}\text { Environmental } \\
\text { Management }\end{array}$ & & Rio Xiangjiang & China & 6 & PQ; NIO & O'Connor e Dobbins \\
\hline Mostafavi et al. & 2011 & Procedia Computer Science & $\sqrt{ }$ & & & 4 & NA-ACO & QUAL2K \\
\hline Hernandez et al. & 2012 & $\begin{array}{l}\text { Clean Technologies and } \\
\text { Environmental Policy }\end{array}$ & & $\begin{array}{l}\text { Rio Arroyo } \\
\text { Colorado }\end{array}$ & $\begin{array}{l}\text { Fronteira } \\
\text { EUA- } \\
\text { México }\end{array}$ & 12 & $\begin{array}{l}\text { SSD; SIG; } \\
\text { SRFNP; HGPA }\end{array}$ & $\sqrt{ }$ \\
\hline Han et al. & 2012 & $\begin{array}{l}\text { KSCE Journal of Civil } \\
\text { Engineering }\end{array}$ & & Rio Nakdong & $\begin{array}{l}\text { Coreia do } \\
\text { Sul }\end{array}$ & 19 & SMC & QUAL2E \\
\hline Zhang et al. & 2012 & $\begin{array}{l}\text { Procedia Environmental } \\
\text { Sciences }\end{array}$ & & Rio Weihe & China & 6 e 9 & $\begin{array}{l}\text { Coeficiente de } \\
\text { Gini; OGP }\end{array}$ & $\sqrt{ }$ \\
\hline Andrade et al. & 2013 & $\begin{array}{l}\text { Journal of Water Resources } \\
\text { Planning and Management }\end{array}$ & & $\begin{array}{l}\text { Rio Santa } \\
\text { Maria da } \\
\text { Vitória }\end{array}$ & Brasil & 5 & WMO-SA & QUAL2E \\
\hline Cho et al. & 2014 & Water Air Soil Pollution & & Rio Yeongsan & $\begin{array}{l}\text { Coreia do } \\
\text { Sul }\end{array}$ & 44 & $\begin{array}{l}\text { Coeficiente de } \\
\text { Gini; NSGA-II }\end{array}$ & QUAL2KW \\
\hline Estalaki et al. & 2014 & $\begin{array}{l}\text { Environmental Earth } \\
\text { Sciences }\end{array}$ & & Rio Zarjub & Irã & 7 & TJEA; AG & $\sqrt{ }$ \\
\hline Ashtiani et al. & $2015 a$ & $\begin{array}{l}\text { International Journal of } \\
\text { Environmental Research }\end{array}$ & & Rio Haraz & Irã & & MOPSO & S\&P \\
\hline Ashtiani et al. & $2015 b$ & $\begin{array}{l}\text { Environmental Monitoring } \\
\text { and Assessment }\end{array}$ & & Rio Haraz & Irã & 8 & $\begin{array}{l}\text { MOPSO; } \\
\text { NSGA-॥I }\end{array}$ & $S \& P$ \\
\hline Santoro et al. & 2016 & RBRH & & Rio Pardo, ES & Brasil & 5 & $\begin{array}{l}\text { AG; Curva de } \\
\text { Lorentz }\end{array}$ & QUAL-UFMG \\
\hline Valory et al. & 2016 & $\begin{array}{c}\text { Journal of Environmental } \\
\text { Engineering }\end{array}$ & & $\begin{array}{l}\text { Rio Santa } \\
\text { Maria da } \\
\text { Vitória, ES }\end{array}$ & Brasil & 5 & $\begin{array}{l}\text { AG; Busca } \\
\text { Exaustiva }\end{array}$ & QUAL-UFMG \\
\hline Yu et al. & 2016 & Journal of Hydrology & & Rio Songhua & China & & $\begin{array}{l}\text { Coeficiente de } \\
\text { Gini; AHP }\end{array}$ & WASP \\
\hline Fantin et al. & 2017 & RBRH & & Rio Pardo, ES & Brasil & 5 & AG; CPL & QUAL-UFMG \\
\hline Saberi et al. & 2017 & $\begin{array}{l}\text { Water Science and } \\
\text { Technology }\end{array}$ & & Rio Sefidrud & Irã & 15 & $\begin{array}{l}\text { MOPSO; } \\
\text { GMCRIl; } \\
\text { MCDM }\end{array}$ & $S \& P$ \\
\hline Xu et al. & 2017 & $\begin{array}{l}\text { Environmental Science and } \\
\quad \text { Pollution Research }\end{array}$ & & Rio Tuojiang & China & 8 & $\begin{array}{l}\text { Coeficiente } \\
\text { Gini; } \\
\text { Condições de } \\
\text { KKT }\end{array}$ & $\sqrt{ }$ \\
\hline Zeferino et al. & 2017 & $\begin{array}{l}\text { Water Science and } \\
\text { Technology }\end{array}$ & & Rio Una, PE & Brasil & 38 & $\begin{array}{c}\text { SA; } \\
\text { Procedimento } \\
\text { de busca local }\end{array}$ & $\sqrt{ }$ \\
\hline Bringer et al. & 2018 & RBRH & & Rio Pardo, ES & Brasil & 5 & $\begin{array}{l}\text { AG; ELECTRE } \\
\text { III }\end{array}$ & QUAL-UFMG \\
\hline Sá et al. & 2019 & RBRH & & Rio Pardo, ES & Brasil & 5 & $A G$ & QUAL-UFMG \\
\hline Saadatpour et al. & 2019 & Journal of Hydroinformatics & & Rio Gheshlagh & Irã & 8 & S-O; PDMOSA & QUAL2Kw \\
\hline
\end{tabular}

Legenda: AG: Algoritmo Genético; AHP: Analytic Hierarchy Process; CPL: Custo Presente Líquido; CRG: Cooperative Reallocation Game; CSM: Cost Saving Maximization; EE: Estação Elevatória; GMCRII: Graph Model for Conflict Resolution II; HGPA: Hybrid Goal-Programming Approach; HM: Homomorphous Mapping; KKT: Karush-Kuhn-Tucker; MCDM: Multi-Criteria Decision Making; MOPSO: Multiobjective Particle Swarm Optimization; NA-ACO: Non-dominated Archiving Multi-colony Ant Algorithm; NIO: Nonlinear Interval Optimization; NSGA-II: Non-Dominated Sorting Genetic Algorithm II; OGP: Optimal Generation Performance; PDMOSA: Pareto Domination-based Multi-objective Simulated Annealing; PL: Programação Linear; PNL: Programação Não Linear; PQ: Programação Quadrática; RNA: Rede Neural Artificial; S\&P: Streeter\&Phelps; SA: Simulated Annealing; SIG: Sistema de Informação Geográfica; SMC: Simulação de Monte Carlo; S-O: Simulação-Otimização; SRFNP: Sensoriamento Remoto para Fontes Não Pontuais; SSD: Sistema de Suporte à Decisão; SST: Sólidos Suspensos Totais; TJEA: Teoria dos Jogos Evolutivos Assimétricos; WMO-SA: Weighted Multi-Objective Simulated Annealing; YBT: Young Bargaining Theory. 
Tabela 2 - Principais objetivos e restrições do PAES

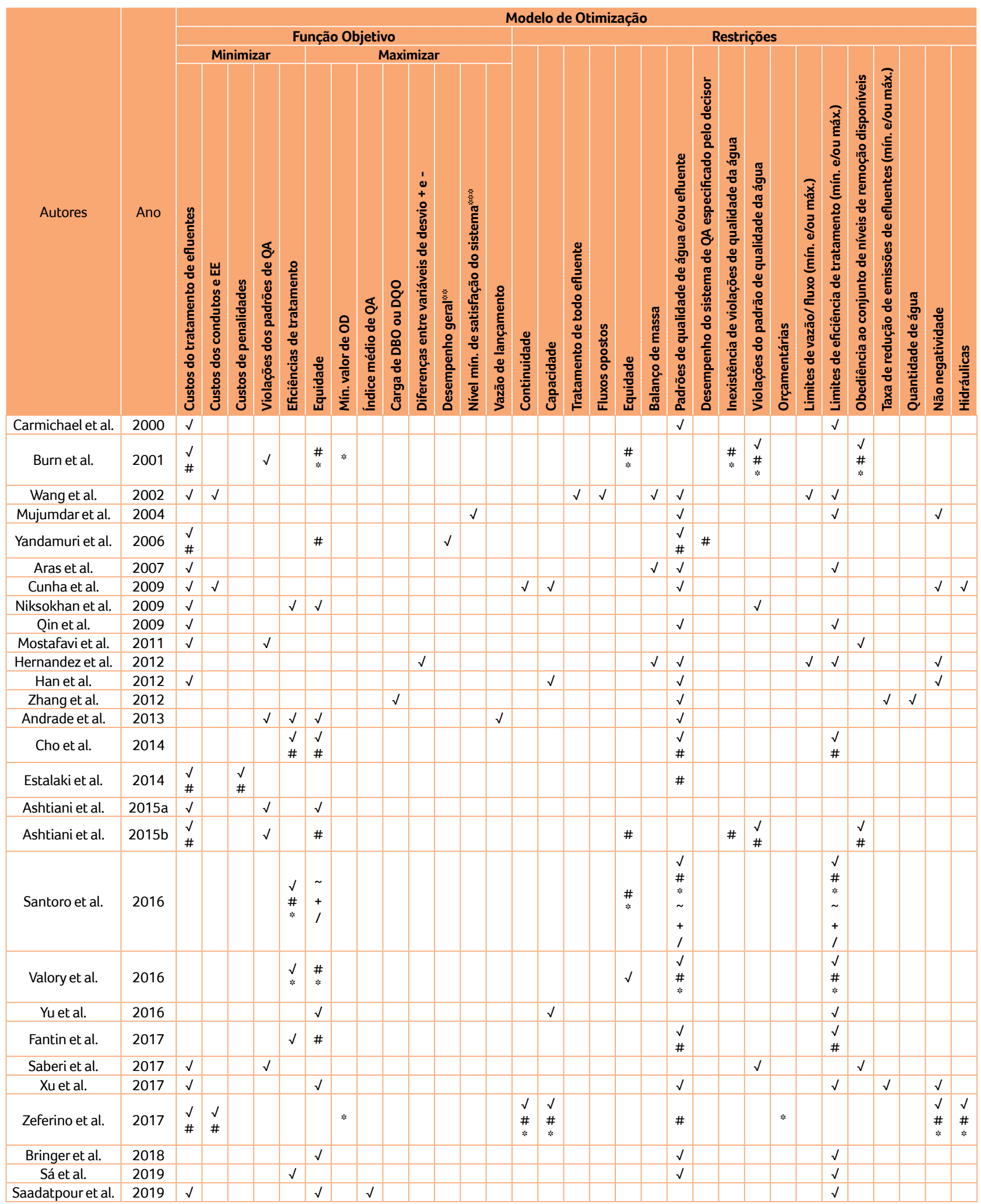

Modelo 1: $\sqrt{ }$ Modelo 2: \# Modelo 3:* Modelo 4: Modelo 5: + Modelo 6: /

*: Soma ponderada de três medidas individuais de desempenho: EN ( $n^{\circ}$ de violações de OD), EV (magnitude da violação máxima de OD) e ETS (magnitude total de violações de OD).

:*:* Conforme taxas de remoção de efluentes 
Niksokhan, Kerachian e Karamouz (2009) combinaram NSGA-II com teoria dos jogos. A metodologia consistiu em duas etapas principais: (i) alocação inicial do custo do tratamento, na qual um modelo de simulação da qualidade da água do rio foi incorporado ao NSGA-II e à Young Bargaining Theory (YBT); (ii) realocação equitativa do custo do tratamento, por meio de abordagens teóricas de jogos cooperativos. A utilidade prática da metodologia proposta foi ilustrada por meio de estudo de caso do rio Zarjub, norte do Irã, curso d'água que possui condição de qualidade de água crítica.

Conforme estudo anterior, pesquisadores têm utilizado a teoria dos jogos para resolver conflitos entre partes interessadas no âmbito de bacias hidrográficas. Além de Niksokhan, Kerachian e Karamouz (2009), ressalta-se o estudo de Estalaki, Abed-Elmdoust e Kerachian (2015), autores que propuseram um PAES baseado em Teoria dos Jogos Evolutivos Assimétricos (TJEA). A metodologia foi desenvolvida de maneira a determinar funções de penalidade que garantissem a qualidade da água do rio, penalizando qualquer poluidor que violasse os padrões estabelecidos. Para isso o framework possuía quatro módulos: (i) simulação da qualidade da água, (ii) cálculo de custos de tratamento de águas residuárias, (iii) funções de penalidade e (iv) modelo TJEA. A aplicação foi feita com dados do rio Zarjub, norte do Irã. Os resultados obtidos pelo TJEA foram comparados aos de um modelo tradicional de alocação de carga visando à minimização de custos e ao atendimento aos padrões de qualidade de água. Observaram-se custos menores ao empregar o modelo tradicional; no entanto, ambos apresentaram respostas semelhantes.

Outra abordagem observada frequentemente nos estudos listados na Tabela 1 é o Multiobjective Particle Swarm Optimization (MOPSO). Ashtiani, Niksokhan e Jamshidi (2015a) aplicaram as equações de Streeter-Phelps no rio Haraz, no Irã, e posteriormente o MOPSO. Os autores encontraram cargas diárias máximas totais que minimizavam as violações dos padrões de qualidade ambiental, os custos totais de tratamento e um índice de inequidade para região. Os custos foram obtidos usando uma função real derivada de ETEs construídas no país no intervalo de 2010 a 2013. Resultados demonstraram uma economia de aproximadamente $41 \%$ nos custos totais em comparação com a política de comando e controle atualmente aplicada na região. 0 estudo de Ashtiani, Niksokhan e Ardestani (2015b), semelhante ao anterior, utilizou novamente Streeter-Phelps, MOPSO e o rio Haraz, no Irã, como área de estudo. $O$ diferencial foi a comparação de duas abordagens para a resolução do problema de otimização: MOPSO e NSGA-II. Os resultados indicaram convergência entre as soluções dos dois algoritmos. Os autores recomendaram fortemente o uso de medidas de equidade para obtenção de uma política mais justa de alocação de carga de efluentes na bacia hidrográfica, ainda que essa escolha nem sempre resulte em um resultado mais econômico.

Saberi e Niksokhan (2017) também utilizaram MOPSO para tratativa do PAES. Inicialmente obtiveram uma curva de trade-off entre os dois objetivos: (i) minimização das violações do padrão de qualidade estabelecido para DBO versus (ii) minimização do custo total do tratamento. Em seguida, a melhor solução não dominada foi selecionada empregando-se conjuntamente MultiCriteria Decision Making (MCDM) e Graph Model for Conflict Resolution II (GMCRII). A aplicabilidade e eficiência da metodologia foram examinadas em um estudo de caso no rio Sefidrud, na parte norte do Irã.

Por outro lado, Andrade, Mauri e Mendonça (2013) propuseram um modelo de otimização tendo como objetivos a minimização dos custos de tratamento, a maximização das descargas de poluentes, a minimização da medida de equida- 
de e a minimização das violações dos padrões de qualidade ambiental fixados para OD e DBO. A bacia hidrográfica do rio Santa Maria da Vitória, Brasil, constituiu a área de estudo avaliada pelos referidos autores. Para aplicação do modelo de otimização foi empregado algoritmo Weighted Multi-Objective Simulated Annealing (MOSA) acoplado ao modelo de simulação de qualidade de água QUAL2E.

Prosseguindo com estudos que fizeram uso combinado de diferentes técnicas para a resolução do PAES, ressalta-se Mujumdar e Subbarao Vemula (2004); Qin et al. (2009) e Hernandez e Uddameri (2013). Mujumdar e Subbarao Vemula (2004) integraram um modelo de otimização fuzzy, o modelo de qualidade de água QUAL2E, um método de manipulação de restrições para algoritmos evolutivos nomeado Homomorphous Mapping (HM) e o AG. O objetivo era obter níveis ótimos de remoção de poluentes para as oito fontes pontuais localizadas na bacia do rio Tunga-Bhadra, no sul da Índia, além do nível de satisfação correspondente. Qin et al. (2009), com auxílio de programação quadrática, minimizaram custos operacionais de sistemas de tratamento de efluentes sujeitos a padrões de qualidade da água e restrições de níveis mínimo e máximo de remoção de carga orgânica. A não linearidade associada à função objetivo foi mitigada pela técnica de regressão quadrática. Incertezas associadas a parâmetros de qualidade da água foram tratadas por meio de análise de intervalo.

Por fim, Hernandez e Uddameri (2013) desenvolveram um Sistema de Suporte à Decisão que incorporou expressões de balanço de massa, Sistema de Informação Geográfica (SIG) e sensoriamento remoto para fontes não pontuais. Um modelo híbrido de programação por metas ou Goal-Programming (GP) foi desenvolvido. A função objetivo buscou maximizar o somatório da diferença entre as duas variáveis de decisão: $Z_{j}^{+}$e $Z_{j}^{-}$. A variável $Z_{j}^{+}$representa o fluxo adi- cional de efluentes que poderia ser descarregado da $E T E_{j}$. A variável $Z_{j}^{-}$, por sua vez, corresponde à quantidade de esgoto que deveria ser reduzido na $E T E_{j}$ para atender os objetivos de qualidade da água no rio. A aplicação foi feita no Rio Arroyo Colorado, fronteira entre EUA e México, região na qual aproximadamente $35 \%$ da população vive na faixa de pobreza. Resultados indicaram que, embora a bacia hidrográfica não tenha atingido seu limite crítico geral, as sub-bacias hidrográficas a montante e a jusante possuem necessidade de redução de suas cargas. Além disso, notou-se que apesar das áreas urbanas cobrirem apenas $13 \%$ da bacia hidrográfica, elas contribuíram com quase $45 \%$ do total de cargas não pontuais.

Explorando outras abordagens de solução para o PAES, podem-se listar Mostafavi e Afshar (2011), que empregaram QUAL2K junto com o Non-dominated Archiving Multi-Colony Ant Algorithm (NA-ACO). A aplicabilidade foi demonstrada por meio de um sistema hídrico hipotético com quatro fontes poluidoras. Buscou-se a minimização dos custos totais do tratamento de esgotos e de um índice de violação de padrão de qualidade ambiental. $O$ índice foi obtido a partir da soma ponderada de três componentes: número de violações do padrão, magnitude da violação máxima e número total de violações do padrão de qualidade estabelecido para OD nos pontos de verificação ao longo do rio. A diminuição do índice de violação, com a consequente melhoria da qualidade da água, levou ao aumento do custo total associado ao tratamento de esgotos. Adicionalmente, ao se elevar o padrão para o parâmetro OD de 6,0 para $6,5 \mathrm{mg} / \mathrm{l}$, a diferença no custo do tratamento entre as soluções de menor custo e da solução com índice mínimo de violação aumentou 73,6\%.

Zhang et al. (2012) estabeleceram um método de alocação de carga para a área Xi'an-Xianyang, rio Weihe, China. Para análise no nível regional, os autores usaram o coeficiente de Gini, o que de- 
monstrou a necessidade de redução de $20 \%$ das concentrações de demanda química de oxigênio (DQO) em oito distritos da região estudada. Em seguida, com auxílio do método Optimal Generation Performance (OGP), os autores estabeleceram o percentual de redução de DQO para alcance da meta global definida no modelo regional.

Yu, He e Lu (2016) também trabalharam com coeficiente de Gini como parâmetro para apoio à solução do PAES. Para o cálculo do coeficiente de Gini foram utilizados como índices de avaliação: população, PIB, área agrícola e capacidade ambiental. Além disso, os pesos dos índices de controle foram determinados por meio do emprego da Análise Hierárquica de Processos (AHP). A aplicação foi realizada na bacia do rio Songhua, China. A estratégia ótima identificada pela modelagem poderia garantir o cumprimento das metas de planejamento do Plano de Ação da China para o Controle da Poluição das Águas.

Xu et al. (2017) propuseram um modelo de otimização em dois níveis, com incertezas integradas. O método incorporou conflitos entre tomadores de decisão e poluidores, além do trade-off entre desenvolvimento socioeconômico e proteção ambiental. A abordagem metodológica foi aplicada ao rio Tuojiang, China, e as soluções do modelo foram obtidas usando a condição KarushKuhn-Tucker (KKT).

É possível observar que grande parte dos artigos citados trabalhou apenas com análises de OD e/ou DBO. No entanto, Carmichael e Strzepek (2000) incluíram, além de DBO, o nitrogênio (N) e o fósforo $(P)$. A utilidade do PAES com múltiplos poluentes foi demonstrada por meio de três abordagens: (i) considerando apenas a redução de DBO; (ii) considerando a redução de $\mathrm{DBO}, \mathrm{P}$ e $\mathrm{N}$ sem levar em consideração sua interação biológica e química; e (iii) considerando a redução de $\mathrm{DBO}, \mathrm{P}$ e $\mathrm{N}$, incluindo interações. Os resultados do estudo de caso na bacia hidrográfica do rio Nitra, Eslováquia, demonstraram que considerar apenas a redução da DBO levou a custos mais altos.

Assim como Carmichael e Strzepek (2000), Han et al. (2012) trabalharam com DBO, N e o P em suas análises. Os autores utilizaram simulação de Monte Carlo (SMC) para minimização dos custos de tratamento de efluentes, estimando as porcentagens de remoção de cargas de resíduos para atender aos padrões de qualidade de água da bacia hidrográfica do rio Nakdong, na Coreia. A incorporação da abordagem estocástica considerou incertezas devido à variação dos conjuntos de dados de vazão e qualidade da água, produzindo resultados mais realistas.

Recentemente, Sá et al. (2019) estabeleceram um modelo de otimização visando à determinação simultânea de eficiências mínimas de remoção de DBO e compostos de $\mathrm{N}$. Os resultados indicaram que, com o aumento de $\mathrm{pH}$ nos cursos d'água, os sistemas precisam ser mais eficientes quanto à remoção de amônia, em função do potencial aumento da sua toxicidade.

Por fim, Saadatpour, Afshar e Khoshkam (2019) empregaram o QUAL2Kw, para simulação de DBO, OD, amônia (NH4-N), nitrato (NO3-N), fosfato (PO4-P), Sólidos suspensos totais (SST) e coliformes, em conjunto com a técnica de otimização Pareto Domination-based Multi-objective Simulated Annealing (PDMOSA). Os objetivos incluíram minimizar os custos de instalação, operação e manutenção das ETEs, maximizar equidade entre lançamentos e maximizar o índice de qualidade da água do rio. Os resultados foram apresentados na forma de uma frente de Pareto, integrando uma combinação das melhores soluções dos três objetivos listados anteriormente. A metodologia foi aplicada a bacia hidrográfica do rio Gheshlagh, Irã, que possui alta carga de efluentes devido ao crescimento abrupto da região, aliado a ausência de tratamento. Resulta- 
dos indicaram que para a fonte pontual de maior carga foi alocado o maior esforço de tratamento, resultado decorrente das medidas de equidade empregadas.

Apesar dos avanços percebidos nas pesquisas de 2000 a 2019, foi possível detectar uma lacuna científica quanto a estudos que englobem o PAES em conjunto com os modelos de localização e dimensionamento de Sistemas Regionais de Tratamento de Efluentes (SRTE). Ou seja, modelos que permitam definir os melhores locais e o dimensionamento de ETEs, estações elevatórias e condutos, agregando informações do percentual de remoção das plantas de tratamento e, consequentemente, do tipo de tratamento mais adequado para o sistema hídrico analisado. Os artigos que mais se aproximaram da abordagem conjunta foram Wang e Jamieson (2002); Cunha et al. (2009) e Zeferino, Cunha e Antunes (2017).

Wang e Jamieson (2002) buscaram determinar uma solução de custo mínimo para a localização das ETEs, bem como o ótimo grau de tratamento. Entretanto, não consideraram problemas de design da rede de esgoto, e a dinâmica da qualidade da água do rio foi analisada somente em termos de Demanda Bioquímica de Oxigênio (DBO) modelada por meio de Redes Neurais Artificiais (RNA). Com o objetivo de encontrar configurações ótimas para redes de tratamento de efluentes, Zeferino, Cunha e Antunes (2017) propuseram três cenários de otimização: (i) minimização dos custos de instalação, operação e manutenção das ETEs, condutos e estações elevatórias, considerando apenas restrições de cunho hidráulico; (ii) inclusão de restrições de qualidade da água ao modelo anterior; (iii) maximização do valor mínimo de OD com um limite de orçamento. No entanto, os autores classificaram as ETEs em pequena e grande escala, assumindo que as ETEs forneciam um determinado nível de tratamento fixo. Cunha et al. (2009) usaram essa mesma abordagem para as ETEs, implementando um algoritmo SA com um procedimento de busca local, procedimento que foi aplicado em diferentes cenários com variações na topografia da região e nas combinações de restrições ambientais do modelo. De forma geral, notou-se que as soluções aproveitaram a topografia da região localizando as ETEs a jusante. Quando os requisitos de qualidade da água se tornaram mais severos, algumas estações permaneceram alocadas a montante para permitir o cumprimento da legislação.

\subsection{Fase III: Realização da Revisão}

Nesta subseção será apresentada apenas a etapa 7 da Fase III, uma vez que a etapa 8 representa a própria elaboração do artigo.

\subsubsection{Etapa 7: Analisar Resultados}

A Fig. 7 evidencia que, quanto à aplicação dos modelos, $10,7 \%$ dos artigos trabalharam apenas com cenários hipotéticos. Os outros $89,3 \%$ foram testados com dados reais de sistemas hídricos presentes em diferentes países (Fig. 7a). Em média, as bacias hidrográficas tinham doze fontes pontuais de esgoto. Ou seja, ainda que existam avanços computacionais, as instâncias de teste não costumam ser extremamente amplas. Uma parcela disso relaciona-se também com a baixa presença de dados disponíveis.

Em relação às instâncias reais, a maioria das publicações foi aplicada em bacias hidrográficas do Brasil, totalizando sete artigos, seguido por Irã e China. Apenas $11,5 \%$ dos países especificados na Fig. 7c são desenvolvidos, conforme classificação do Fundo Monetário Internacional (ONU, 2017). Os demais se enquadram no grupo de países emergentes, com economias em desenvolvimento ou que recentemente se estabeleceram como economias desenvolvidas (Fig. 7b). Nesse contexto, o emprego combinado de técnicas de otimização e de modelagem matemática da qua- 
lidade da água pode apresentar-se como uma alternativa válida para planejamento e seleção de sistemas de tratamento de esgotos. Isso porque a implantação de estações de tratamento de esgoto (ETE) é geralmente uma tarefa do governo. A redução dos esforços de tratamento - com a consequente redução de investimentos na implantação e operação das estações - permite a redistribuição de recursos públicos poupados para outras demandas sociais (REIS; VALORY;
MENDONÇA, 2015; SANTORO; REIS; MENDONÇA, 2016). É necessário enfatizar que a adoção de um objetivo de minimização de custos não significa menor preocupação com questões ambientais. De fato, o que a função objetivo significa é que buscou-se a solução de menor custo consistente com os objetivos especificados para a qualidade da água por meio das restrições, o que pode ser extremamente exigente (CUNHA et al. 2009).

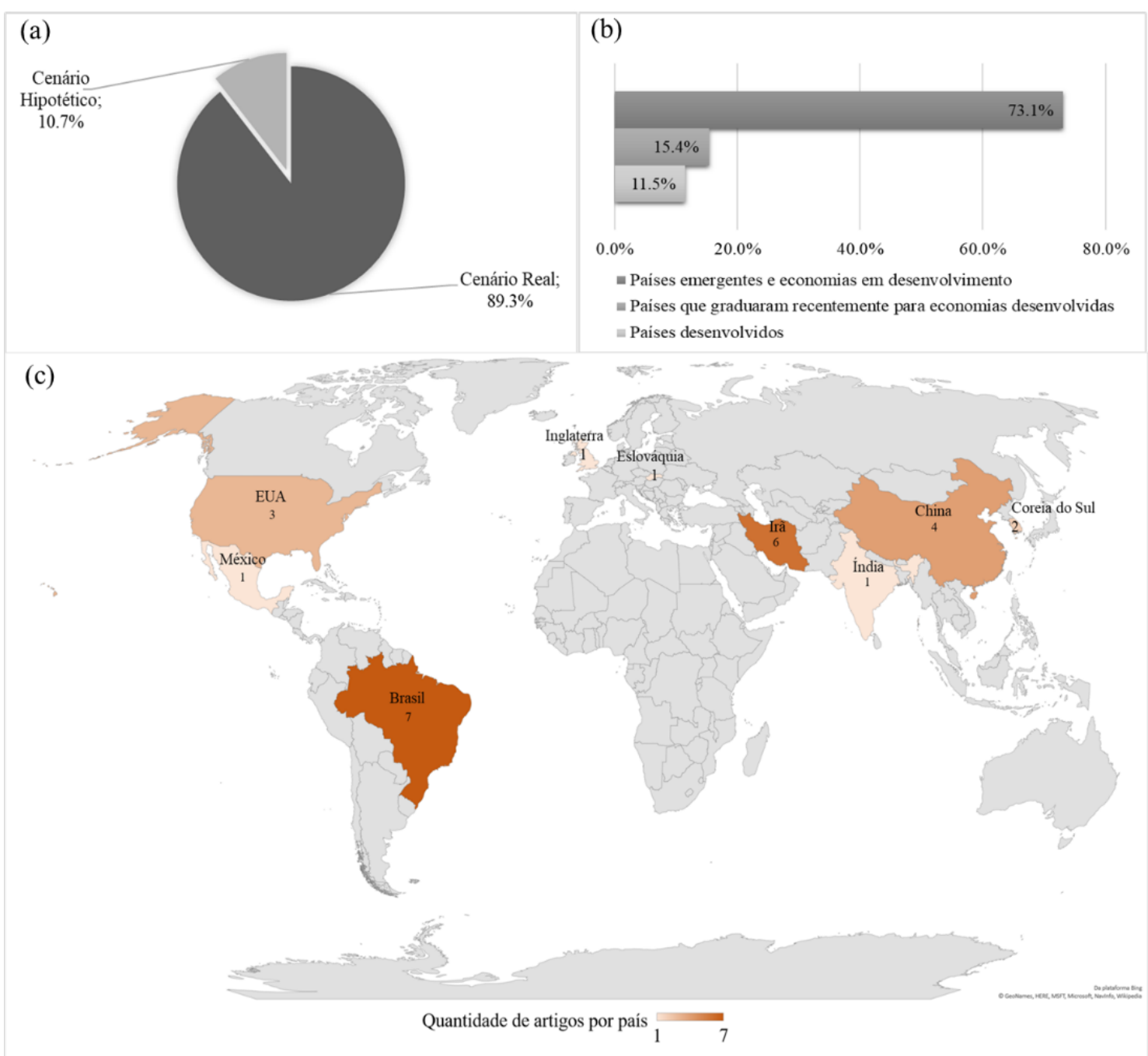

Figura 7 - (a) Tipos de cenários; (b) PAES versus desenvolvimento dos países; (c) Aplicação do PAES em países. 
Quanto ao modelo de qualidade de água que foi acoplado ao método de otimização, sete artigos não mencionaram claramente qual modelo utilizado. O restante dos estudos empregou QUAL2E, QUAL-UFMG, Streeter-Phelps, QUAL2Kw, O'Connor e Dobbins, QUAL2K, TOMCAT e WASP, sendo os três primeiros modelos empregados em $71,4 \%$ dos trabalhos analisados. A formulação original e precursora do modelo de Streeter-Phelps foi, ao longo dos anos, modificada e aperfeiçoada, ainda mantendo sua estrutura conceitual clássica e sendo recorrentemente empregada até os dias atuais (WANG et al., 2013). O QUAL2E (BROWN; BARNWELL, 1987) é um dos modelos de qualidade da água mais conhecidos e utilizados por pesquisadores de diversas regiões do mundo (COX,
2003; VON SPERLING, 2014), sendo empregado, em inúmeros trabalhos, como ferramenta de suporte para o gerenciamento de recursos hídricos (PALIWAL; SHARMA; KANSAL, 2007; AZZELLINO et al., 2006; NING et al., 2001).

Posteriormente, com base no QUAL2E, foi desenvolvido o modelo QUAL-UFMG, modelo mais recorrentemente utilizado no Brasil (SALLA et al., 2013; TEODORO et al., 2013; ZANDONADI; MENDONÇA; REIS, 2015; CALMON et al., 2016). Considerando a presença maciça de artigos com aplicação em bacias hidrográficas brasileiras (Fig. 7c), é justificável a indicação do modelo QUAL-UFMG em percentual elevado nesta revisão sistemática.

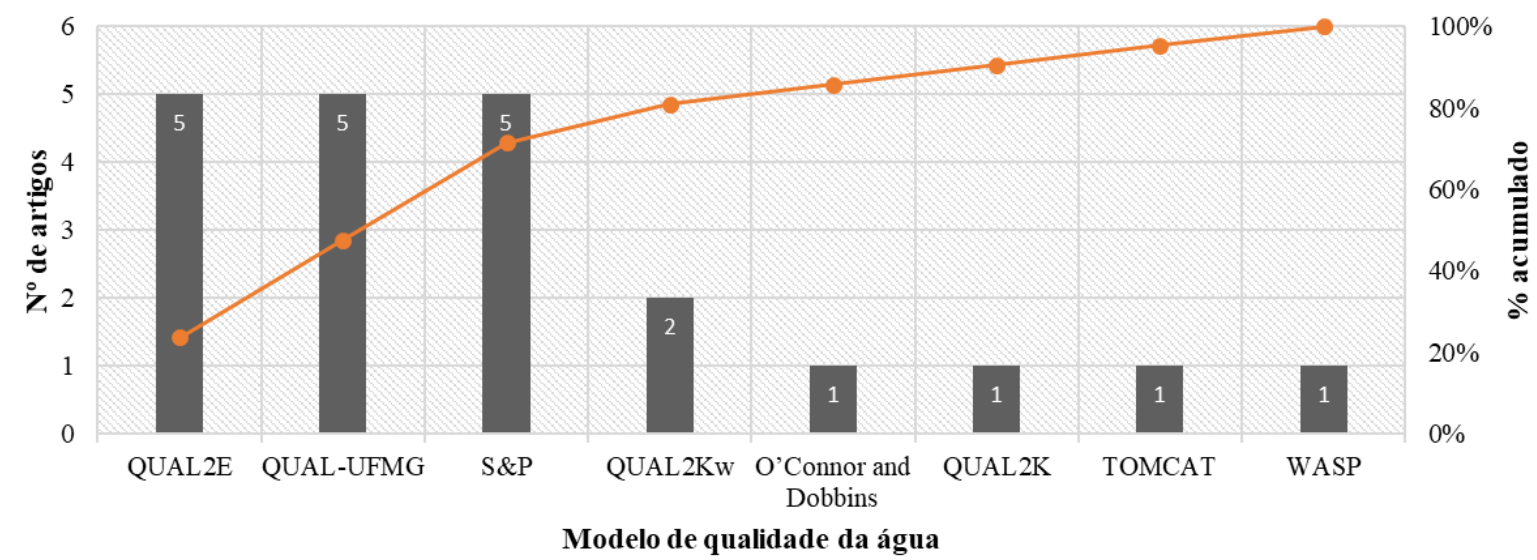

Figura 8 - Uso de modelos de qualidade da água nos PAES

Os parâmetros mais utilizados na caracterização de corpos d'água e no controle operacional de estações de tratamento de efluentes foram o OD e a DBO (Fig. 9). O aprimoramento dos modelos usados, das técnicas de otimização e uma maior conscientização da necessidade de coleta e acompanhamento de dados levaram à inclusão de novos parâmetros ao longo do período acompanhado nesta revisão (2000-2019). Nesse contexto, os estudos passaram a incluir os parâmetros nitrogênio, fósforo, amônia, dentre outros (Fig. 9). 


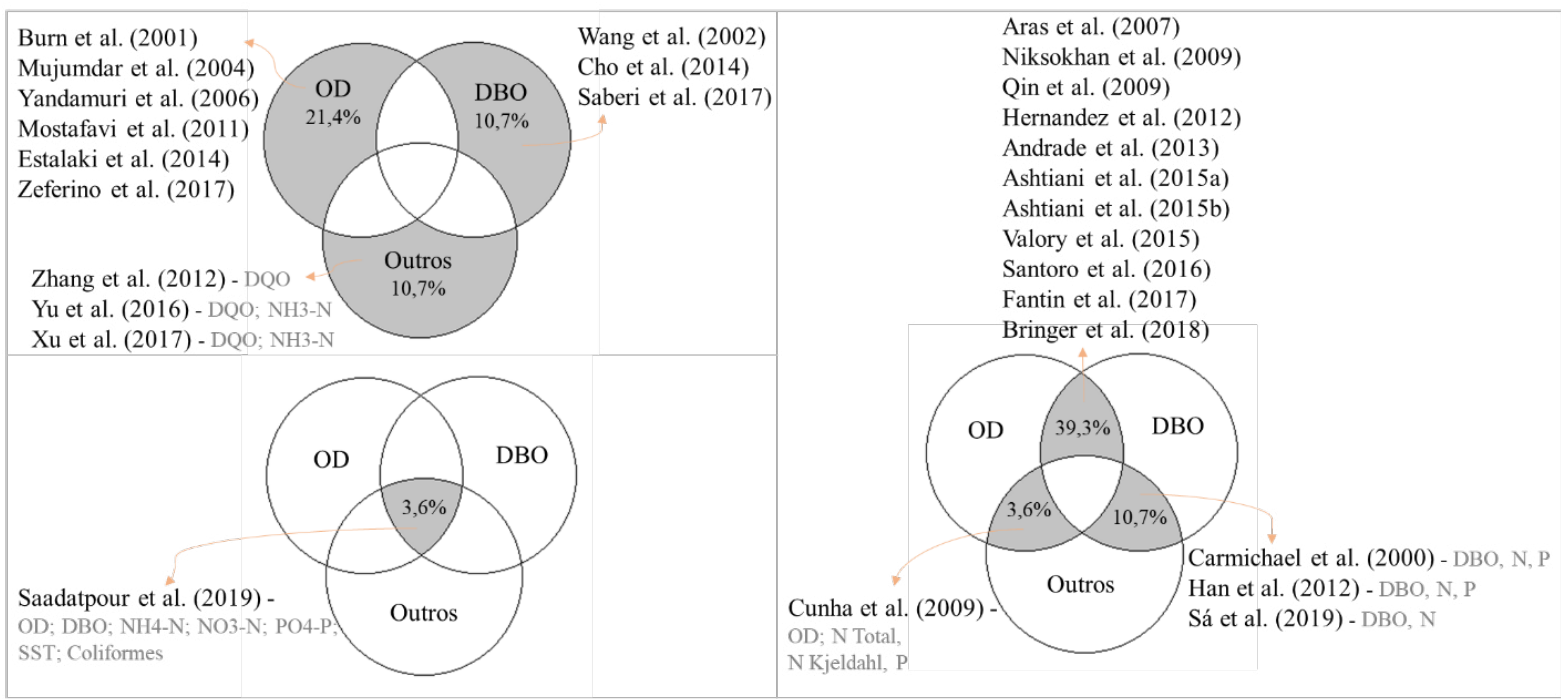

Legenda: DBO: Demanda Bioquímica de Oxigênio; DQO: Demanda Química de Oxigênio; N: Nitrogênio; NH4-N: Amônia; NIO: Nonlinear Interval Optimization; NO3-N: Nitrato; OD: Oxigênio Dissolvido; P: Fósforo; PO4-P: Fosfato; SST: Sólidos Suspensos Totais.

Figura 9 - Parâmetros de qualidade da água analisados

A partir da análise dos artigos listados na Tabela 1, notou-se o uso principal de Algoritmo Genético (AG) como abordagem de solução para o PAES. Dos 28 artigos listados, 10 utilizaram essa metaheurística. Em seguida, $14 \%$ dos artigos trabalharam com NSGA-II, uma das mais conhecidas variações do $A G$. Esses dados ressaltam o êxito dos AGs na busca de soluções para o PAES. Outras abordagens que também surgiram com certa frequência foram Multiobjective Particle Swarm Optimization (MOPSO), Procedimento de Busca Local e Simulated Annealing (SA).

O modelo clássico de alocação de carga efluente visa a minimização dos custos sujeito a restrições de cunho ambiental, conforme Tabela 2. A amostra de dados dessa revisão sistemática confirmou esse padrão. No entanto, notou-se uma tendência crescente do uso de múltiplos objetivos, atestado inclusive pela presença de abordagens de solução mais robustas ao longo dos anos. Seguido da minimização dos custos, há a maximização de medidas de equidade e a minimização do somatório de eficiências de re- moção de efluentes que, implicitamente, sugerem a minimização dos custos (Fig.10).

Um ponto a se ressaltar sobre a inclusão dos custos em PAES é que apenas três artigos incluíram, explicitamente, os custos de manutenção dos sistemas de tratamento e que sete artigos incluíram os custos de operação. Em geral, apenas os custos de instalação das ETEs foram utilizados no processo de busca de solução do PAES. Esse aspecto é consequência da ausência ou da dificuldade de obtenção de dados para elaboração das funções de custos (MACHADO, 2009).

Ainda conforme Fig. 10, restrições relacionadas à legislação ambiental vigente são comumente usadas no PAES. No entanto, é relevante destacar que existe uma tendência de crescimento de pesquisas com enfoque em medidas de equidade entre os esforços de tratamento, uma vez que a capacidade de assimilação de efluentes pelos corpos d'água deve ser adequadamente rateada entre os poluidores para que, além dos ganhos econômicos, ocorram ganhos sociais. 


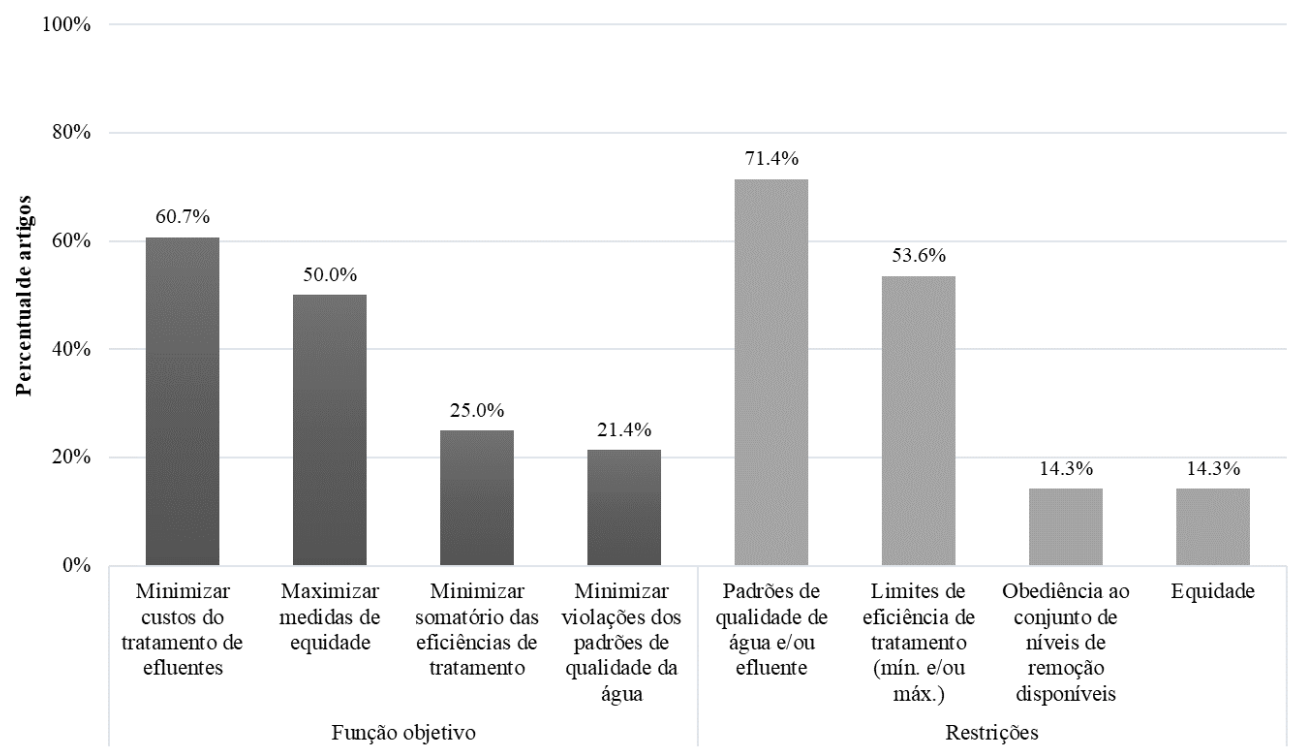

Figura 10 - Objetivos e restrições do PAES

Por fim, foi possível notar que as soluções de planejamento para problemas de sistemas de águas residuárias são frequentemente buscadas em nível local (ZEFERINO, 2011). Nesse caso, há ETEs individuais localizadas em cada ponto de geração de efluentes. A abordagem na qual os efluentes sanitários de diferentes localidades sejam agrupados em plantas de tratamento de abrangência regional é ainda escassa. É importante salientar que, ao agrupar esgotos vindos de diferentes localidades em uma ETE central, há necessidade de considerar restrições que envolvam a formulação clássica dos Problemas de Localização de Facilidades (PLF), ou seja, todo o esgoto gerado precisa ser tratado, e restrições de capacidade e de continuidade de fluxo, obedecidas. Quanto ao objetivo, a função deve incluir custos de transporte, contemplando a inserção de estações elevatórias, quando necessário, e dos condutos. Assim, a solução conterá a localização e capacidade das ETEs, o diâmetro da tubulação em cada trecho, bem como a disposição dos sistemas de transporte e a localização das elevatórias quando necessárias (CUNHA et al., 2009; MELO; CÂMARA, 1994; ZEFERINO, 2011). Assim, a junção desses dois aspectos constitui uma lacuna científica nesta área de pesquisa. Ambos, PAES e PLF, caracterizam-se pela complexidade de solução prática e, em geral, a construção de resoluções vem sendo desenvolvida separadamente, ainda que os temas sejam, de certa maneira, interdependentes.

\section{CONCLUSÕES}

Neste artigo foi apresentada uma revisão sistemática da literatura para o Problema de Alocação de Efluentes Sanitários (PAES), dando ênfase, especialmente, aos cenários de aplicação, aos modelos de qualidade da água aplicados, aos métodos de resolução e aos objetivos e restrições incluídos nos modelos de otimização, aspectos que consistem nos principais fatores de diferenciação entre as publicações. Por meio da metodologia empregada nesta revisão sistemática, entendem-se como relevantes as seguintes conclusões e contribuições:

- Dentre as abordagens de solução para o PAES, a grande maioria foi composta por Algoritmos Genéticos e suas variações. Além disso, a maior parte das aplicações usaram cenários reais ao invés de cenários hipotéticos; 
- A maior parte dos países que realizaram a aplicação do PAES em artigos classificam-se como emergentes ou economicamente em desenvolvimento. Ao considerar uma população global crescente e que enfrenta restrições de recursos, a mudança de paradigmas e uma gestão de recursos hídricos que permita soluções mais econômicas e simultaneamente ambientalmente seguras ganha relevância. Dessa maneira, a carência de recursos pode justificar a incorporação do conceito de autodepuração no processo de escolha de sistemas de tratamento de águas residuárias. Ressalta-se que o uso de cursos d'água como complementação dos processos de tratamento de esgotos deve ser realizado com parcimônia e dentro de critérios tecnicamente seguros e bem definidos;

- Frequentemente incluídas nos modelos de otimização analisados, as medidas de equidade permitiram que a capacidade de assimilação de efluentes pelos corpos d'água fosse rateada entre os poluidores, evitando que um só poluidor utilizasse toda a capacidade de assimilação do curso d'água;

- Uma lacuna científica no que diz respeito a metodologias que tratem da alocação de cargas orgânicas em conjunto com o planejamento de redes de tratamento de efluentes em nível regional foi observada. Notou-se uma escassez de trabalhos que considerem não apenas os elementos individualmente - condutos, estações de tratamento de efluentes, elevatórias e corpo receptor - mas também as interações existentes entre eles;

- Por fim, verificou-se que o uso combinado de técnica de otimização e modelo computacional de qualidade de água para o desenvolvimento de problemas de alocação de efluentes sanitários pode subsidiar e fundamentar tomadas de decisões relativas à seleção dos sistemas de tratamento de esgotos no âmbito de bacias hidrográficas.

\section{AGRADECIMENTOS}

À Capes pelo apoio financeiro à pesquisa.

\section{CONTRIBUIÇÃO DOS AUTORES}

Conceitualização: Gomes TC, Mendonça ASF, Reis JAT; Metodologia: Gomes TC, Rosa RA; Levantamento bibliográfico: Gomes TC; Análise dos resultados: Gomes TC, Mendonça ASF, Reis JAT, Rosa RA; Redação: Gomes TC; Revisão primeira versão: Mendonça ASF, Reis JAT, Rosa RA; Revisão final e edição: Gomes TC.

\section{REFERÊNCIAS}

AGÊNCIA NACIONAL DE ÁGUAS (ANA) - BRASIL. Atlas esgotos: despoluição de bacias hidrográficas / Agência Nacional de Águas, Secretaria Nacional de Saneamento Ambiental. Brasília: ANA, 2017. Disponível em: http://atlasesgotos.ana.gov.br/Release. Atlas.Esgotos.pdf. Acesso em: 18 de junho de 2019.

ANDRADE, L. N.; MAURI, G. R.; MENDONÇA, A. S. F. General multiobjective model and simulated annealing algorithm for waste-load allocation. Journal of Water Resources Planning and Management, v. 139, n. 3, p. 339-344, 2013. https://doi. org/10.1061/(ASCE)WR.1943-5452.0000257

ARAS, E; TOGAN, V; BERKUN, M. River water quality management model using genetic algorithm. Enviromental Fluidic Mechanical, v. 7, p. 439-450, 2007. https://doi.org/10.1007/s10652-0079037-4

ARPINI, B. P.; ROSA, R. A. Uma revisão sistemática da literatura sobre o Problema de Roteirização de Veículos Capacitados com Restrições de Carregamento Bidimensional (2L-CVRP). Transportes, v. 25, n. 1, p. 61-72, 2017. https://doi.org/10.14295/ transportes.v25i1.867

ASHTIANI, E. F., NIKSOKHAN, M. H., JAMSHIDI, S. Equitable fund allocation, an economical approach for sustainable waste load allocation. Environmental monitoring and assessment, v. 187, n. 8, p. 522, 2015a. https://doi.org/10.1007/s10661-015-4739-4

ASHTIANI, E. F.; NIKSOKHAN, M. H.; ARDESTANI, M. Multi-objective Waste Load Allocation in River System by MOPSO Algorithm. International Journal of Environmental Research, v. 9, n. 1, p. 69-76, 2015b.

AZZELLINO, A., SALVETTI, R., VISMARA, R., BONOMO, L. Combined use of the EPA-QUAL2E simulation model and factor analysis to assess the source apportionment of point and nonpoint loads of nutrients to surface waters. Science of the total 
environment, 371(1), 214-222, 2006. https://doi.org/10.1016/j. scitotenv.2006.03.022

BRAGA, B; BARBOSA, P. S. F; NAKAYAMA, P.T. Sistemas de suporte à decisão em recursos hídricos. RBRH, v. 3, n. 3, p. 73 - 95, 1998. https://doi.org/10.21168/rbrh.v3n3.p73-95

BRERETON, P.; B. A. KITCHENHAM; D. BUDGEN; M. TURNER E M. KHALIL. Lessons from applying the systematic literature review process within the software engineering domain. Journal of systems and software, v. 80, n. 4, p. 571-583, 2007. https://doi. org/10.1016/j.jss.2006.07.009

BRINGER, L. M. Seleção de sistemas de tratamento de esgotos no âmbito de bacias hidrográficas a partir do emprego de modelagem de qualidade, otimização e da análise multiobjetivo. Dissertação (Mestrado em Engenharia Ambiental) - Universidade Federal do Espírito Santo, Vitória, ES. 2017.

BRINGER, L. M., REIS, J. A. T. D., MENDONÇA, A. S. F. Seleção de sistemas de tratamento de esgotos no âmbito de bacias hidrográficas a partir do emprego da análise multiobjectivo. RBRH, v. 23, 2018. https://doi.org/10.1590/2318-0331.231820170140

BROWN, L. C.; BARNWELL Jr, T. O. The Enhanced Stream Water Quality Models QUAL2E and QUAL2E-UNCAS: Documentation and User Manual. Georgia: EPA, 1987.

BURN, D. H.; YULIANTI; J. S. Waste-load allocation using genetic algorithms. Journal of Water Resources Planning and Management, 127(2), 121-129, 2001. https://doi.org/10.1061/ (ASCE)0733-9496(2001)127:2(121)

CALMON, A. P. S. Metodologia para suporte ao processo de enquadramento dos cursos d'água superficiais considerando curvas de permanência de qualidade e processo de autodepuração. Dissertação (Mestrado em Engenharia Ambiental) - Universidade Federal do Espírito Santo, Vitória, ES. 2015.

CALMON, A. P. S.; SOUZA, J. C. S.; REIS, J. A. T.; MENDONÇA, A. S. F. Uso combinado de curvas de permanência de qualidade e modelagem da autodepuração como ferramenta para suporte ao processo de enquadramento de cursos d'água superficiais. Revista Brasileira de Recursos Hídricos, 21(1), 118-133, 2016. https://doi.org/10.21168/rbrh.v21n1.p118-133

CARMICHAEL, J. J.; STRZEPEK, K. M. A multiple organic pollutant simulation/optimization model of industrial and municipal wastewater loading to a riverine environment. Water Resources Research, v. 36, n. 5, p. 1325-1332, 2000. https://doi. org/10.1029/2000WR900010

CHAPRA, S. C. Surface water-quality modeling. Waveland press, 2008.

CHO, J. H.; LEE, J. H. Multi-objective Waste Load Allocation Model for Optimizing Waste Load Abatement and Inequality Among Waste Dischargers. Water Air Soil Pollution, 2014. https://doi. org/10.1007/s11270-014-1892-2
COX, B. A. A review of currently available in-stream water-quality models and their applicability for simulating dissolved oxygen in lowland rivers. Science of the Total Environment, v. 314, p. 335377, 2003. https://doi.org/10.1016/S0048-9697(03)00063-9

CUNHA, M. C., PINHEIRO, L., AFONSO, P., SOUSA, J. A multi-objective approach for wastewater system planning at a regional level. WIT Transactions on Ecology and the Environment, v. 80, 2005.

CUNHA, M. C.; PINHEIRO, L.; ZEFERINO, J.; ANTUNES, A.; AFONSO, P. Optimization model for integrated regional wastewater systems planning. Journal of water resources planning and management, 135(1), 23-33, 2009. https://doi.org/10.1061/ (ASCE)0733-9496(2009)135:1(23)

DEB, K., PRATAP, A., AGARWAL, S., \& MEYARIVAN, T. A. M. T. A fast and elitist multiobjective genetic algorithm: NSGA-II. IEEE transactions on evolutionary computation, v. 6, n. 2, p. 182-197, 2002. https://doi.org/10.1109/4235.996017

DORFMAN, R.; JACOBY, H. D.; THOMAS, H. A. Models for managing regional water quality. Harvard University Press, Cambridge, Mass, 1972.

ESTALAKI, S. M., ABED-ELMDOUST, A., KERACHIAN, R. Developing environmental penalty functions for river water quality management: application of evolutionary game theory. Environmental Earth Sciences, v. 73, n. 8, p. 4201-4213, 2015. https://doi.org/10.1007/s12665-014-3706-7

FANTIN, L. L. D.; REIS, J. A. T. dos; MENDONÇA, A. S. F. Proposal of a methodology for pre-selection of sewage treatment systems within watersheds. RBRH, v. 22, 2017. https://doi. org/10.1590/2318-0331.011716079

HAN, K., NOH, J., KIM, J. S., LEE, C. Application of stochastic optimization algorithm for waste load allocation in the Nakdong River basin, Korea. KSCE Journal of Civil Engineering, v. 16, n. 4, p. 650-659, 2012. https://doi.org/10.1007/s12205-012-0919-8

HERNANDEZ, E. A.; UDDAMERI, V. An assessment of optimal waste load allocation and assimilation characteristics in the Arroyo Colorado River watershed, TX along the US-Mexico border. Clean Technologies and Environmental Policy, v. 15, n. 4, p. 617-631, 2013. https://doi.org/10.1007/s10098-012-0546-6

KARMAKAR, S.; MUJUMDAR, P. P. Grey fuzzy optimization model for water quality management of a river system. Advances in Water Resources, v. 29, n. 7, p. 1088-1105, 2006. https://doi. org/10.1016/j.advwatres.2006.04.003

LANNA, A. E. Gestão de Recursos Hídricos - In: Tucci C. E. M. (Org) - Hidrologia: ciência e aplicação. Associação Brasileira de Recursos Hídricos - ABRH. 2 ed. São Paulo: EDUSP. 1997.

LEI, K., ZHOU, G., GUO, F., KHU, S. T., MAO, G., PENG, J., LIU, Q. Simulation-optimization method based on rationality evaluation for waste load allocation in Daliao river. Environmental earth sciences, v. 73, n. 9, p. 5193-5209, 2015. https://doi.org/10.1007/ s12665-015-4334-6 
LIU, D.; GUO, S.; SHAO, Q.; JIANG, Y.; CHEN, X. Optimal allocation of water quantity and waste load in the Northwest Pearl River Delta, China. Stochastic environmental research and risk assessment, v. 28, n. 6, p. 1525-1542, 2014. https://doi.org/10.1007/s00477013-0829-4

LOUCKS, D. P.; REVELLE, C. S.; LYNN, W. R. Linear programming models for water pollution control. Management Science, 14(4), B166-B181, 1967. https://doi.org/10.1287/mnsc.14.4.B166

MACHADO, E. S. Utilização da metaheurística de recozimento simulado na otimização do planejamento de sistemas regionais de tratamento de efluentes e sua expansão da capacidade. São Paulo. Tese (Doutorado em Engenharia Civil - Recursos Hídricos). Escola Politécnica da Universidade de São Paulo, 2009.

MACHADO, E. S.; CUNHA, M. C.; PORTO, M. Otimização de sistemas regionais de sistemas de tratamento de efluentes e seu impacto na qualidade da água: uma revisão. REGA - Vol. 3, no. 1, p. 57-71, jan./jun. 2006.

MACHADO, E. S.; PORTO, M. F. A.; KAVISKI, E. Otimização do Planejamento de Sistemas Regionais de Tratamento de Efluentes Através de Simulação Monte Carlo e da Metaheurística do Recozimento Simulado. RBRH - Revista Brasileira de Recursos Hídricos. Volume 17, 2012. https://doi.org/10.21168/rbrh.v17n3. p29-38

MAHJOURI, N.; BIZHANI-MANZAR, M. Waste load allocation in rivers using fallback bargaining. Water resources management, v. 27 , n. 7, p. 2125-2136, 2013. https://doi.org/10.1007/s11269013-0279-2

MELO, J. J.; CÂMARA, A.S. Models for the optimization of regional wastewater treatment systems. European Journal of Operational Research,v.73, n. 1, p. 1-16, 1994. https://doi.org/10.1016/03772217(94)90134-1

METCALF, L.; EDDY, H. P.; TCHOBANOGLOUS, G. Wastewater Engeneering: treatment, disposal, and reuse. $3^{\mathrm{a}}$ ed. New York, McGraw- Hill, 1991.

MEZURA-MONTES, E.; COELLO, C. A. C. Constrained optimization via multiobjective evolutionary algorithms. In: Multiobjective problem solving from nature. Springer, Berlin, Heidelberg, p. 5375, 2008. https://doi.org/10.1007/978-3-540-72964-8_3

MOSTAFAVI, S. A.; AFSHAR, Abbas. Waste load allocation using non-dominated archiving multi-colony ant algorithm. Procedia Computer Science, v. 3, p. 64-69, 2011. https://doi.org/10.1016/j. procs.2010.12.012

MUJUMDAR, P. P.; SUBBARAO VEMULA, V. R. Fuzzy waste load allocation model: simulation-optimization approach. Journal of Computing in Civil Engineering, v. 18, n. 2, p. 120-131, 2004. https://doi.org/10.1061/(ASCE)0887-3801(2004)18:2(120)

NIKOO, M. R.; KERACHIAN, R.; NIKSOKHAN, M. H. Equitable waste load allocation in rivers using fuzzy Bi-matrix games. Water resources management, v. 26, n. 15, p. 4539-4552, 2012. https:// doi.org/10.1007/s11269-012-0165-3

NIKSOKHAN, M. H.; KERACHIAN, R.; KARAMOUZ, M. A game theoretic approach for trading discharge permits in rivers. Water Science and Technology, v. 60, n. 3, p. 793-804, 2009. https://doi. org/10.2166/wst.2009.394

NING, S. K.; CHANG, N. B.; YANG, L.; CHEN, H. W.; HSU, H. Y. Assessing pollution prevention program by QUAL2E simulation analysis for the Kao-Ping River Basin, Taiwan. Journal of Environmental Management, 61(1), 61-76, 2001. https://doi. org/10.1006/jema.2000.0397

OKOLI, C., SCHABRAM, K. A Guide to Conducting a Systematic Literature Review of Information Systems Research. Sprouts: Working Papers on Information Systems, 10(26), 2010. https:// doi.org/10.2139/ssrn.1954824

ONU - List of Least Developed Countries, 2017.

PALIWAL, R.; SHARMA, P.; KANSAL, A. Water quality modelling of the river Yamuna (India) using QUAL2E-UNCAS. Journal of Environmental Management, v. 83 p. 131-144, 2007. https://doi. org/10.1016/j.jenvman.2006.02.003

QIN, X., HUANG, G., CHEN, B., ZHANG, B. An interval-parameter waste-load-allocation model for river water quality management under uncertainty. Environmental management, v. 43, n. 6, p. 999-1012, 2009. https://doi.org/10.1007/s00267-009-9278-8

RAUCH, W.; HENZE, M.; KONCSOS, L.; REICHERT, P.; SHANAHAN, P.; SOMLYÓDY, L.; VANROLLEGHEM, P. River water quality modelling: I. State of the art. Water Science and Technology, 38(11), 237-244, 1998. https://doi.org/10.1016/S0273-1223(98)00660-X

REIS, J. A. T.; VALORY, J. L.; MENDONÇA, A. S. F. Seleção de eficiências de tratamento de esgotos a partir da manutenção de equidade entre sistemas de tratamento: uma abordagem para - gerenciamento de bacias hidrográficas. Revista Brasileira de Recursos Hídricos, v. 20, n. 4, p. 862-871, 2015. https://doi. org/10.21168/rbrh.v20n4.p862-871

REVELLE, C. S.; LOUCKS, D. P.; LYNN, W. R. Linear programming applied to water quality management. Water Resources Research, v. 4, n. 1, p. 1-9, 1968. https://doi.org/10.1029/ WR004i001p00001

SÁ, G. L. N.; REIS, J. A.T.; MENDONÇA, A. S. F.; SILVA, F. G. B. Methodology for minimum nitrogen compounds removal efficiencies estimation and wastewater treatment systems pre-selection: a watershed approach. RBRH, v. 24, p. e41, 2019. https://doi.org/10.1590/2318-0331.241920180173

SAADATPOUR, M.; AFSHAR, A.; KHOSHKAM, H. Multi-objective multi-pollutant waste load allocation model for rivers using coupled archived simulated annealing algorithm with QUAL2Kw. Journal of Hydroinformatics, v. 21, n. 3, p. 397-410, 2019. https://doi.org/10.2166/hydro.2019.056 
SABERI, L.; NIKSOKHAN, M. H. Optimal waste load allocation using graph model for conflict resolution. Water Science and Technology, v. 75, n. 6, p. 1512-1522, 2017. https://doi. org/10.2166/wst.2016.429

SALLA, M. R.; PEREIRA, C. E.; ALAMY FILHO, J. E.; PAULA, L. M. D.; PINHEIRO, A. M. Estudo da autodepuração do Rio Jordão, localizado na bacia hidrográfica do Rio Dourados. Revista Engenharia Sanitária e Ambiental, 18(2), 105-114, 2013. https://doi.org/10.1590/S1413-41522013000200002

SANTORO, M. C.; REIS, J. A. T.; MENDONÇA, A. S. F. Performance evaluation of optimization models in the determination of wastewater treatment efficiencies inside watersheds. RBRH, v. 21 , n. 4 , p. $694-706$, 2016. https://doi.org/10.1590/23180331.011616031

SRINIVAS, N.; DEB, K. Muiltiobjective optimization using nondominated sorting in genetic algorithms. Evolutionary computation, v. 2, n. 3, p. 221-248, 1994. https://doi. org/10.1162/evco.1994.2.3.221

STREETER, H.W.; PHELPS E.B. A Study of the Pollution and Natural Purification of the Ohio River. Public Health Bulletin, 146. Washington D.C.: U.S. Public Health Service, 1925.

TEODORO, A.; IDE, C. N.; RIBEIRO, M. C.; BROCH, S. A. O.; DA SILVA, J. B. Implementação do conceito Capacidade de Diluição de Efluentes no modelo de qualidade da água QUAL-UFMG: estudo de caso no Rio Taquarizinho (MS). Eng. Sanit. Ambient, 18(3), 275-288, 2013. https://doi.org/10.1590/S141341522013000300010

VALORY, J. P. L.; REIS, J. A. T.; MENDONÇA, A. S. F. Combining genetic algorithms with a water quality model to determine efficiencies of sewage treatment systems in watersheds. Journal of Environmental Engineering, v. 142, n. 3, p. 04015080, 2016. https://doi.org/10.1061/(asce)ee.1943-7870.0001048

VON SPERLING, M. Estudos e Modelagem da Qualidade da Água de Rios. 2. ed. Belo Horizonte: Editora UFMG, 2014.

VON SPERLING, M. Wastewater Characteristics, Treatment and Disposal: Biological Wastewater Treatment Series - Vol. 1. London: IWA Publishing. 2007.
WANG, C. G.; JAMIESON, D. G. An objective approach to regional wastewater treatment planning. Water resources research, v. 38, n. 3, p. 4-1-4-8, 2002. https://doi.org/10.1029/2000WR000062

WANG, Q.; LI, S.; JIA, P.; QI, C.; DING, F. A review of surface water quality models. The Scientific World Journal, v. 2013, 2013. https://doi.org/10.1155/2013/231768

XU, J., HOU, S., YAO, L., \& LI, C. Integrated waste load allocation for river water pollution control under uncertainty: a case study of Tuojiang River, China. Environmental Science and Pollution Research, v. 24, n. 21, p. 17741-17759, 2017. https://doi. org/10.1007/s11356-017-9275-z

YANDAMURI, S. R.; SRINIVASAN, K.; MURTY BHALLAMUDI, S. Multiobjective optimal waste load allocation models for rivers using nondominated sorting genetic algorithm-ll. Journal of water resources planning and management, v. 132, n. 3, p. 133-143, 2006. https://doi.org/10.1061/(ASCE)07339496(2006)132:3(133)

YU, S.; HE, L.; LU, H. An environmental fairness based optimisation model for the decision-support of joint control over the water quantity and quality of a river basin. Journal of Hydrology, v. 535, p. 366-376, 2016. https://doi.org/10.1016/j.jhydrol.2016.01.051

ZANDONADI, L. U.; MENDONÇA, A. S. F.; REIS, J. A. T. Outorga de lançamento de efluentes em rios - estimativas de vazões de diluição. Revista Brasileira de Recursos Hídricos, v. 20, n. 1, p. 179-191, 2015. https://doi.org/10.21168/rbrh.v20n1.p179-191

ZEFERINO, J. A. D. Optimization models for wastewater systems planning at regional level: deterministic and robust approaches. Tese de Doutorado, Universidade de Coimbra. Portugal, 2011.

ZEFERINO, J. A.; CUNHA, M. C.; ANTUNES, A. P. Adapted optimization model for planning regional wastewater systems: case study. Water Science and Technology, v. 76, n. 5, p. 11961205, 2017. https://doi.org/10.2166/wst.2017.302

ZHANG, Y., WANG, X. Y., ZHANG, Z. M., \& SHEN, B. G. Multi-level waste load allocation system for Xi'an-Xianyang section, Weihe river. Procedia Environmental Sciences, v. 13, p. 943-953, 2012. https://doi.org/10.1016/j.proenv.2012.01.088

ZITZLER, E.; THIELE, L. An evolutionary algorithm for multiobjective optimization: The strength pareto approach. TIK-report, v. 43, 1998. 